9700 South Cass Avenue, Argonne, nlinois 60439

Engineering, Equipment, and Instruments (UC-406)

\title{
Chaotic Dynamics of Loosely Supported Tubes
} in Crossflow

by

Y. Cai and S. S. Chen

Materials and Components Technology Division

July 1991

Work supported by

U.S. DEPARTMENT OF ENERGY

Office of Basic Energy Sciences

\section{MASTER}




\section{Contents}

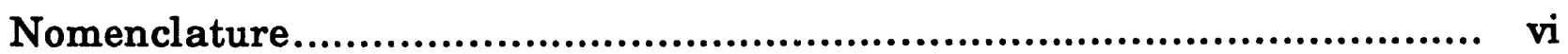

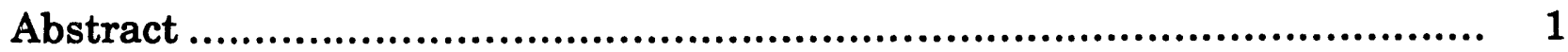

1 Introduction .................................................................... 1

2 Equations of Motion .............................................................. 3

3 A Bilinear Model for Loosely Supported Tubes ................................ 6

4 Numerical Results and Discussion ...................................... 9

4.1 Critical Flow Velocity.......................................................... 10

4.2 Bifurcation Diagram........................................................... 16

4.3 Phase Portraits ............................................................. 18

4.4 Power Spectral Density........................................................... 21

4.5 Poincaré Map.................................................................... 27

5 Conclusions...................................................................... 29

Acknowledgments............................................................. 32

References........................................................................ 32

Appendix: Modal Analysis of a Bilinear Model ................................... 37 


\section{Figures}

1 Tube row oscillating in nonuniform crossflow ...........................

$2 \quad$ Schematic of tube and supports in crossflow ............................ 6

3a Schematic of tube with supports $\mathrm{C} 1$ and $\mathrm{C2}$, and right end free ......... 7

3b Schematic of tube with supports $\mathrm{C1}$ and $\mathrm{C2}$, and right end supported by a spring

4 Relationship of reduced flow velocity and mean flow velocity when reass-damping parameter is equal to 0.3 in Model 1 ........................ 12

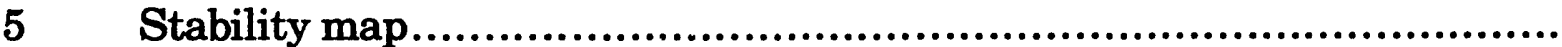

$6 \quad$ System damping vs. reduced flow velocity................................... 14

$7 \quad$ System damping vs. mean flow velocity ............................... 14

8 RMS tube displacement as a function of flow velocity for various diametral gaps...................................................................

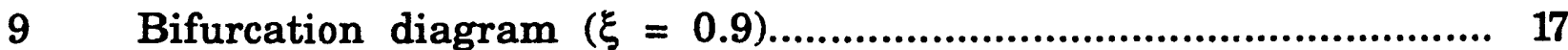

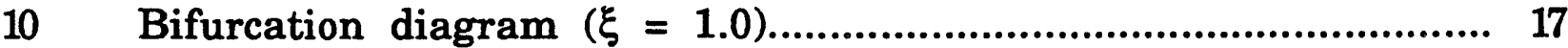

11 Time history of tube displacement, velocity, and motion at $\xi=1.0$ with (a) $U_{m}=1.8 \mathrm{~m} / \mathrm{s}$, (b) $U_{m}=1.7 \mathrm{~m} / \mathrm{s}$, (c) $U_{m}=1.6 \mathrm{~m} / \mathrm{s}$, and (d) $U_{\mathrm{m}}=1.55 \mathrm{~m} / \mathrm{s}$

12 Time history of tube displacement, velocity, and motion at $\xi=0.8$ with (a) $U_{m}=1.8 \mathrm{~m} / \mathrm{s}$, (b) $U_{m}=1.7 \mathrm{~m} / \mathrm{s}$, (c) $U_{m}=1.6 \mathrm{~m} / \mathrm{s}$, and (d) $U_{m}=1.55 \mathrm{~m} / \mathrm{s}$

13 Time history of tube displacement, velocity, and motion at $\xi=0.4$ with (a) $U_{m}=1.8 \mathrm{~m} / \mathrm{s}$, (b) $U_{m}=1.7 \mathrm{~m} / \mathrm{s}$, (c) $U_{m}:=1.6 \mathrm{~m} / \mathrm{s}$, and (d) $\mathrm{U}_{\mathrm{m}}=1.55 \mathrm{~m} / \mathrm{s}$

14 Power spectral density of tube displacement with (a) $U_{m}=1.8 \mathrm{~m} / \mathrm{s}$,

(b) $U_{m}=1.75 \mathrm{~m} / \mathrm{s}$, (c) $U_{m}=1.7 \mathrm{~m} / \mathrm{s}$, (d) $U_{m}=1.67 \mathrm{~m} / \mathrm{s}$,

(e) $U_{m}=1.65 \mathrm{~m} / \mathrm{s}$, (f) $U_{m}=1.62 \mathrm{~m} / \mathrm{s}$, (g) $U_{m}=1.6 \mathrm{~m} / \mathrm{s}$, and

(h) $U_{m}=1.57 \mathrm{~m} / \mathrm{s}$, 
15 Poincaré map of tube motion at $\xi=0.2$ with (a) $U_{m}=1.8 \mathrm{~m} / \mathrm{s}$,

(b) $U_{m}=1.75 \mathrm{~m} / \mathrm{s}$, (c) $U_{m}=1.7 \mathrm{~m} / \mathrm{s}$, (d) $U_{m}=1.67 \mathrm{~m} / \mathrm{s}$,

(e) $U_{m}=1.65 \mathrm{~m} / \mathrm{s}$, (f) $U_{m}=1.6 \mathrm{~m} / \mathrm{s}$, and $(\mathrm{g}) U_{m}=1.55 \mathrm{~m} / \mathrm{s} \ldots \ldots \ldots \ldots \ldots$

\section{Tables}

1 Calculated natural frequencies of a tube...................................... 11

$2 \quad$ Indexing of peaks of Fig. 14....................................................... 28 


\section{Nomenclature}

$a_{j n}, \dot{a}_{j n} \quad$ Generalized tube displacement and velocity in $x$ direction

$b_{j n}, \dot{b}_{j n} \quad$ Generalized tube displacement and velocity in $y$ direction

D Tube diameter

E Young's modulus

e Wall thickness of tube

$e_{1}, e_{2} \quad$ Tube-support gaps

f Oscillation frequency

$f_{n} \quad$ Natural frequency of $n$-th mode

I Moment of inertia of tube cross section

$\mathrm{K}_{\mathrm{c}} \quad$ Equivalent stiffness

$k_{n} \quad$ Eigenvalues for tube vibration

$\ell \quad$ Tube length

$m_{j} \quad$ Mass per unit length of $j$-th tube

$\mathrm{N} \quad$ Number of tubes in array or row

n Number of modes

P Pitch

R Radius of tube

t Time

$t_{s} \quad$ Time when tube strikes TSP

$t_{d} \quad$ Time when tube leaves TSP

U Flow velocity

$\mathrm{U}_{\mathrm{m}} \quad$ Mean flow velocity 
$\mathrm{U}_{\mathrm{r}} \quad$ Reduced flow velocity $\left(=\mathrm{U}_{\mathrm{m}} / \mathrm{fD}\right.$ or $\left.\mathrm{U} / \mathrm{fD}\right)$

$u_{j}, \dot{u}_{j} \quad$ Displacement and velocity of $j$-th tube in $x$ direction

$\mathbf{v}_{\mathbf{j}}, \dot{\mathbf{v}}_{\mathbf{j}} \quad$ Displacement and velocity of $\mathbf{j}$-th tube in $\mathbf{y}$ direction

$\mathrm{x}, \mathrm{y}, \mathrm{z} \quad$ Cartesian coordinates

$\alpha_{j k}, \beta_{j k}, \quad$ Added-mass coefficients

$\sigma_{j k}, \tau_{j k}$

$\alpha_{j k}^{\prime}, \beta_{j k}^{\prime}, \quad$ Fluid damping coefficients

$\sigma_{\mathrm{jk}}, \tau_{\mathrm{jk}}$

$\alpha_{\mathrm{jk}}^{\prime \prime}, \beta_{\mathrm{jk}}^{\prime \prime}, \quad$ Fluid stiffness coefficients

$\sigma_{\mathrm{jk}}, \tau_{\mathrm{jk}}$

$\xi \quad$ Dimensionless coordinates

$\zeta_{j}, \eta_{j} \quad$ Damping ratio in vacuum

$\gamma_{j} \quad$ Mass ratio $\left(=\rho \pi R^{2} / m_{j}\right)$ of $j$-th tube

p Fluid density

$\omega \quad$ Circular frequency

$\omega_{\mathrm{j}}, \Omega_{\mathrm{j}} \quad$ Natural frequency in radian of $\mathrm{j}$-th tube in vacuum

$\varphi_{n}(z) \quad$ Orthonormal function of $n$-th mode

$\Psi(\mathrm{z}) \quad$ Flow velocity distribution function

\section{Subscripts}

$\mathbf{j}, \mathbf{k} \quad$ Tube number $\mathbf{j}, \mathbf{k}(\mathbf{j}, \mathbf{k}=\mathbf{1}$ to $N)$

n n-th modes

$1 \quad$ For Model 1 (TSP-inactive mode)

$2 \quad$ For Model 2 (TSP-active mode) 


\title{
Chaotic Dynamics of Loosely Supported Tubes in Crossflow
}

\author{
by
}

Y. Cai and S. S. Chen

\begin{abstract}
By means of the unsteady-flow theory and a bilinear mathematical model, a theoretical study was conducted of the chaotic dynamics associated with the fluidelastic instability of loosely supported tubes. Calculations were performed for the RMS of tube displacement, bifurcation diagram, phase portrait, power spectral density, and Poincaré map. Analytical results show the existence of chaotic, quasiperiodic, and periodic regions when flow velocity exceeds a threshold value.
\end{abstract}

\section{Introduction}

The supports for heat exchanger tubes are usually plates with drilled holes. To facilitate manufacture and to allow for thermal expansion of the tubes, small clearances are used between tubes and tube supports. When the clearance is relatively large, a tube may rattle inside some of its support holes with smallamplitude oscillations. This type of mode, in which some supports do not provide effective support, is called tube-support-plate (TSP)-inactive mode.

Extensive experimental and analytical studies have been performed on the dynamic response of loosely held tubes and how the tube response is related to wear. ${ }^{1-25}$ Chen et al. ${ }^{1}$ investigated the fluidelastic behavior of loosely held tubes in the laboratory. They observed that as the flow velocity is increased to a threshold value, instability in the TSP-inactive mode may occur. Then, for a range of flow velocities higher than the threshold flow velocity, the tube vibrates predominantly in the TSP-inactive mode, with the response amplitude limited by the clearance between the tube and the TSP. With a further increase in flow velocity, a second threshold, or critical flow velocity, is reached, at which point instability in the TSP-active mode begins. In this case, large-amplitude oscillations occur and, in many cases, tubes may impact one another. Additional experimental studies to determine the response of loosely supported tubes in the TSP-inactive mode under some specific flow conditions have recently been published.7-11 
On the other hand, for analyzing tube responses and impacting behavior of loosely supported tubes, many nonlinear methods have been developed in recent years.12-26 Numerical simulations have been performed by Axisa et al.,20 Fricker, 14 and Rao et al.;15 all used quasistatic or quasisteady-flow theories, which are applicable in specific parameter ranges. Chen and Chandra 23 developed the unsteady-flow model on fluidelastic instability of tubes in nonuniform flow. Cai et al. ${ }^{26}$ presented a bilinear model, based on the unsteadyflow theory. The simulations in Ref. 26 agreed reasonably well with the experimental data of Chen et al. ${ }^{1}$ and demonstrated that the unsteady-flow theory and the bilinear model are adequate to describe the nonlinear behavior of fluidelastic instability associated with TSP-inactive modes of loosely supported tubes in crossflow.

With the recent interest in chaotic motions of nonlinear systems ${ }^{27-30}$ and the relationship of chaotic vibration to tube wear, it is appropriate to look into the possible existence of chaos in tube arrays in crossflow. Related systems without flow have been studied experimentally by several investigators. Moon, Shaw, and Holmes ${ }^{31-34}$ studied forced oscillation of beams with motion constraints; chaos was found to exist. A case study of chaos in a marine application, involving impacting modeled via bilinear springs, was discussed by Thompson and Stewart.29 Recently, it was realized that flow-induced vibration of loosely supported tubes, which is one of the systems with motion constraints, can display a wide variety of dynamic behavior. For example, chaotic fluidelastic vibrations of a constrained pipe conveying fluid were examined by Paidoussis and Moon both experimentally and theoretically, 35,36 with the use of a two-degree of freedom system. And a study on chaotic and periodic motions of a nonlinear oscillator in order to model flow-induced vibration of loosely supported tubes was conducted by Langre et al. 37

The objective of the work presented in this report is to apply the theory of fluidelastic instability of TSP-inactive modes, developed in Ref. 26, to predict the complex periodic/chaotic dynamics of loosely supported tubes in crossflow. The focus is on possible chaotic motions and a route to chaos in the instability region of the TSP-inactive mode.

Several techniques, including root-mean-square (RMS) of tube displacement, bifurcation diagrams, phase portraits, power spectral density, and Poincaré map, which are considered to be effective tools for distinguishing periodis and chaotic motions, were utilized in this study. Many calculations have been carried out to thoroughly confirm the existence of chaotic motion and the route to chaos with change of control parameters (in this study, the only control parameter is flow velocity). The results of various techniques indicate the existence of chaotic motion in the instability region of the TSP-inactive mode. 


\section{Equations of Motion}

An unsteady flow theory for fluidelastic instability of tubes in crossflow has been described in detail by $\mathrm{Chen}^{22}$ and by Chen and Chandra. ${ }^{23}$ For completeness, the unsteady flow model for fluidelastic instability of loosely supported tubes is briefly described here.

Consider a row of $N$ tubes oscillating in a crossflow (Fig. 1). The tube axes are parallel to the $z$ axis. The subscript $j$ is used to denote variables associated with $a$ tube $j$. Tube displacement components in the $x$ and $y$ directions are $u_{j}$ and $\mathrm{v}_{\mathrm{j}}$, respectively. The orthonormal modal function of the tube vibrating in vacuum and in fluid is $\varphi_{n}(z)$ :

$$
\frac{1}{\ell} \int_{0}^{\ell} \varphi_{\mathrm{n}}^{2}(\mathrm{z}) \mathrm{dz}=1
$$

where $\ell$ is the length of the tubes. Let

$$
u_{j}(z, t)=\sum_{n=1}^{\infty} a_{j n}(t) \varphi_{n}(z)
$$

and

$$
\mathrm{v}_{j}(\mathrm{z}, \mathrm{t})=\sum_{n=1}^{\infty} \mathrm{b}_{j n}(\mathrm{t}) \varphi_{\mathrm{n}}(\mathrm{z})
$$
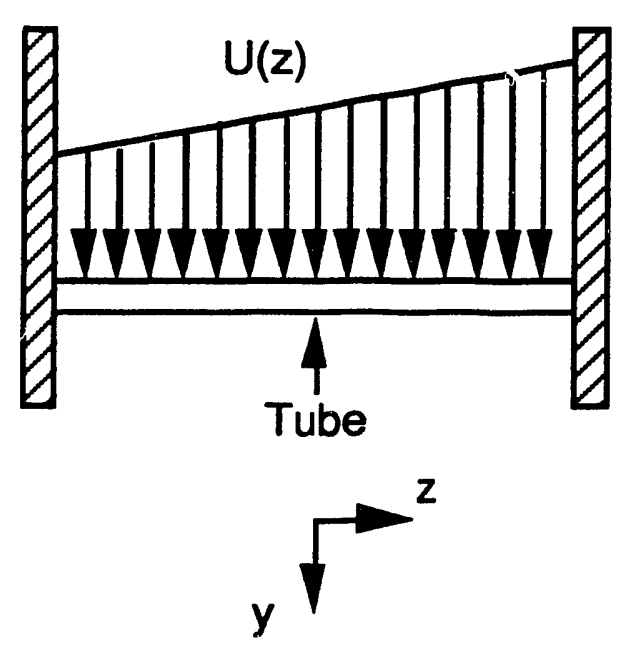

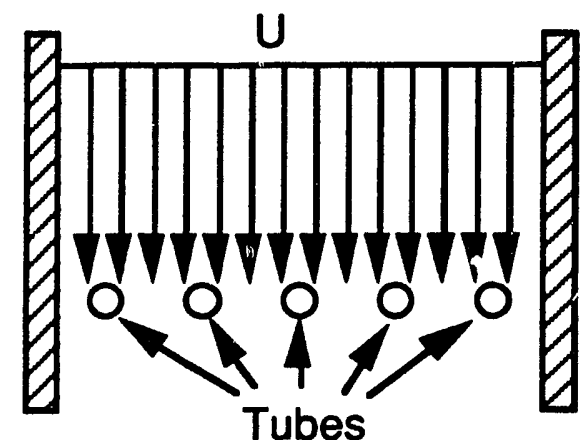

Tubes

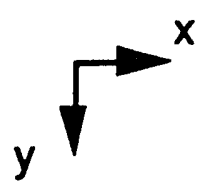

Fig. 1. Tube row oscillating in nonuniform crossflow; $U(z)$ is flow velocity distribution 
where $a_{j n}(t)$ and $b_{j n}(t)$ are functions of time only. Assume that the flow velocity distribution is given by

$$
\mathrm{U}(\mathrm{z})=\mathrm{U}_{\mathrm{m}} \psi(\mathbf{z}),
$$

where $U_{m}$ is mean flow velocity and $\psi(z)$ is the flow velocity distribution function.

The equations of motion for the tubes are

$$
\begin{aligned}
\frac{d^{2} a_{j n}}{d t^{2}} & +2 \zeta_{j n} \omega_{j n} \frac{d a_{j n}}{d t}+\omega_{j n}^{2} a_{j n}+\frac{\rho \pi R^{2}}{m_{j}} \sum_{k=1}^{N}\left(\alpha_{j k} \frac{d^{2} a_{k n}}{d t^{2}}+\sigma_{j k} \frac{d^{2} b_{k n}}{d t^{2}}\right) \\
& -\frac{\rho U_{m}^{2}}{m_{j} \omega} \sum_{k=1}^{N}\left(\alpha_{j k n}^{d} \frac{d a_{k n}}{d t}+\sigma_{j k n}^{d} \frac{d b_{k n}}{d t}\right)-\frac{\rho U_{m}^{2}}{m_{j}} \sum_{k=1}^{N}\left(\alpha_{j k n}^{e} a_{k n}+\sigma_{j k n}^{e} b_{k n}\right)=0,
\end{aligned}
$$

and

$$
\begin{aligned}
\frac{d^{2} b_{j n}}{d t^{2}} & +2 \eta_{j n} \Omega_{j n} \frac{d b_{j n}}{d t}+\Omega_{j n}^{2} b_{j n}+\frac{\rho \pi R}{m_{j}} \sum_{k=1}^{N}\left(\tau_{j k} \frac{d^{2} a_{k n}}{d t^{2}}+\beta_{j k} \frac{d^{2} b_{k n}}{d t^{2}}\right) \\
& -\frac{\rho U_{m}^{2}}{m_{j} \omega} \sum_{k=1}^{N}\left(\tau_{j k n}^{d} \frac{d a_{k n}}{d t}+\beta_{j k n}^{d} \frac{d b_{k n}}{d t}\right)-\frac{\rho U_{m}^{2}}{m_{j}} \sum_{k=1}^{N}\left(\tau_{j k n}^{e} a_{k n}+\beta_{j k n}^{e} b_{k n}\right)=0,
\end{aligned}
$$

where $\rho$ is fluid density; $R$ is tube radius; $\omega$ is the radian frequency; $\zeta_{j n}$ and $\eta_{j n}$ are damping ratios in vacuum; $\omega_{j n}$ and $\Omega_{j n}$ are natural frequencies in the radian of the $j$-th cylinder in vacuum; $m_{j}$ is cylinder mass per unit length of cylinder $j$, and

$$
\begin{array}{ll}
\alpha_{j \mathrm{kn}}^{\mathrm{d}}=\frac{1}{\ell} \int_{0}^{\ell} \alpha_{\mathrm{jk}}^{\prime} \varphi_{\mathrm{n}}^{2}(\mathrm{z}) \psi^{2}(\mathrm{z}) \mathrm{dz}, & \alpha_{\mathrm{jkn}}^{\mathrm{e}}=\frac{1}{\ell} \int_{0}^{\ell} \alpha_{\mathrm{jk}}^{\prime \prime} \varphi_{\mathrm{n}}^{2}(\mathrm{z}) \psi^{2}(\mathrm{z}) \mathrm{dz}, \\
\sigma_{\mathrm{jkn}}^{\mathrm{d}}=\frac{1}{\ell} \int_{0}^{\ell} \sigma_{\mathrm{jk}}^{\prime} \varphi_{\mathrm{n}}^{2}(\mathrm{z}) \psi^{2}(\mathrm{z}) \mathrm{dz}, & \sigma_{\mathrm{jkn}}^{\mathrm{e}}=\frac{1}{\ell} \int_{0}^{\ell} \sigma_{\mathrm{jk}}^{\prime \prime} \varphi_{\mathrm{n}}^{2}(\mathrm{z}) \psi^{2}(\mathrm{z}) \mathrm{dz}, \\
\tau_{\mathrm{jkn}}^{\mathrm{d}}=\frac{1}{\ell} \int_{0}^{\ell} \tau_{\mathrm{jk}}^{\prime} \varphi_{\mathrm{n}}^{2}(\mathrm{z}) \psi^{2}(\mathrm{z}) \mathrm{dz}, & \tau_{\mathrm{jkn}}^{\mathrm{e}}=\frac{1}{\ell} \int_{0}^{\ell} \tau_{\mathrm{jk}}^{\prime \prime} \varphi_{\mathrm{n}}^{2}(\mathrm{z}) \psi^{2}(\mathrm{z}) \mathrm{dz}, \\
\beta_{\mathrm{jkn}}^{\mathrm{d}}=\frac{1}{\ell} \int_{0}^{\ell} \beta_{j \mathrm{jk}}^{\prime} \varphi_{\mathrm{n}}^{2}(\mathrm{z}) \psi^{2}(\mathrm{z}) \mathrm{dz}, & \beta_{\mathrm{jkn}}^{\mathrm{e}}=\frac{1}{\ell} \int_{0}^{\ell} \beta_{j \mathrm{k}}^{\prime \prime} \varphi_{\mathrm{n}}^{2}(\mathrm{z}) \psi^{2}(\mathrm{z}) \mathrm{dz} .
\end{array}
$$


Note that $\alpha_{j k}, \sigma_{j k}, \tau_{j k}$, and $\beta_{j k}$ are added-mass coefficients; $\alpha_{j k}^{\prime}, \sigma_{j k}^{\prime}, \tau_{j k}^{\prime}$, and $\beta_{j k}^{\prime}$ are fluid-damping coefficients; and $\alpha_{j k}^{\prime \prime}, \sigma_{j k}^{\prime \prime}, \tau_{j k}^{\prime \prime}$, and $\beta_{j k}^{\prime \prime}$ are fluid-stiffness coefficients. All these force coefficients are based on the experimental data of Tanaka ${ }^{24}$ and have been compiled and evaluated by Chen and Chandra ${ }^{23}$ and Chen and Jendrzejczyk. 25

Equations 4 and 5 are applicable to tube arrays in which all tubes have the same length and same type of boundary conditions. For a group of $\mathbf{N}$ tubes, corresponding to each $\mathrm{n}$-th mode for a single tube, there are $2 \mathrm{~N}$ coupled modes. Based on Eqs. 4, different types of instability can be analyzed, including coupledand single-mode flutter, or velocity- and displacement-controlled mechanisms.

Consider the case of fluidelastic instability in which a velocity-controlled, negative damping mechanism is dominant. The stability of the tube row may be analyzed approximately by considering only one flexible tube among other rigid tubes and neglecting the coupling in the two directions. For this case, Eqs. 4 can be written as

$$
\left(1+\gamma_{j} \alpha_{j j}\right) \frac{d^{2} a_{j n}}{d t^{2}}+\left(2 \zeta_{j n} \omega_{j n}-\frac{\gamma_{j} U_{r}^{2}}{\pi^{3}} \omega \alpha_{j j}^{d}\right) \frac{d a_{j n}}{d t}+\left(\omega_{j n}^{2}-\frac{\gamma_{j}}{\pi^{3}} U_{r}^{2} \alpha_{j j}^{e}\right) a_{j n}=0,
$$

and

$$
\begin{aligned}
& \left(1+\gamma_{j} \beta_{j j}\right) \frac{d^{2} b_{j n}}{d t^{2}}+\left(2 \eta_{j n} \Omega_{j n}-\frac{\gamma_{j} U_{r}^{2}}{\pi^{3}} \omega \beta_{j j}^{d}\right) \frac{d b_{j n}}{d t}+\left(\Omega_{j n}^{2}-\frac{\gamma_{j}}{\pi^{3}} U_{r}^{2} \beta_{j j}^{e}\right) b_{j n}=0, \\
& j=1,2,3, \ldots N, \quad n=1,2,3, \ldots \infty
\end{aligned}
$$

where

$$
\begin{aligned}
& \gamma_{j}=\frac{\rho \pi R^{2}}{m_{j}}, \\
& U_{r}=\frac{\pi U_{m}}{\omega R},
\end{aligned}
$$

and 


$$
\omega=\sqrt{\frac{\omega_{j n}^{2}-\frac{\gamma_{j}}{\pi^{3}} U_{r}^{2} \alpha_{j \mathrm{j}}^{e}}{1+\gamma_{j} \alpha_{j j}}} .
$$

Notice that $\omega$ depends on the coefficients $\alpha_{\mathrm{jj}}^{\mathrm{e}}$, which depend on the reduced flow velocity $U_{r}\left(=U_{m} / f D=U_{m} \cdot 2 \pi / \omega D\right)$. Therefore, an iterated method is required to calculate $\omega$.

\section{A Bilinear Model for Loosely Supported Tubes}

A two-span flexible tube with one intermediate support in a row of rigid tubes, schematically shown in Fig. 2, was tested by Chen et al. 1 When the right end (C3) of the tube does not strike the stop, it is a pinned-pinned-free model (Model 1, Fig. 3a). When the right end strikes the stop, it becomes a pinnedpinned-spring-supported model (Model 2, Fig. 3b), where a spring at C3 is used to represent tube/support interaction when the tube strikes the stop. Because the effects of impact force are represented by the spring at C3 in Model 2, the vibratory system is autonomous, as described in Eq. 6.

Vibration of the tube can be represented by a bilinear model consisting of Models 1 and 2. In Model 1 , as the displacement of the tube increases, its right end may strike the stop; when this occurs, Model 1 becomes Model 2. Due to increased system stiffness, tube motion is stabilized and its right end leaves the stop and returns to Model 1.

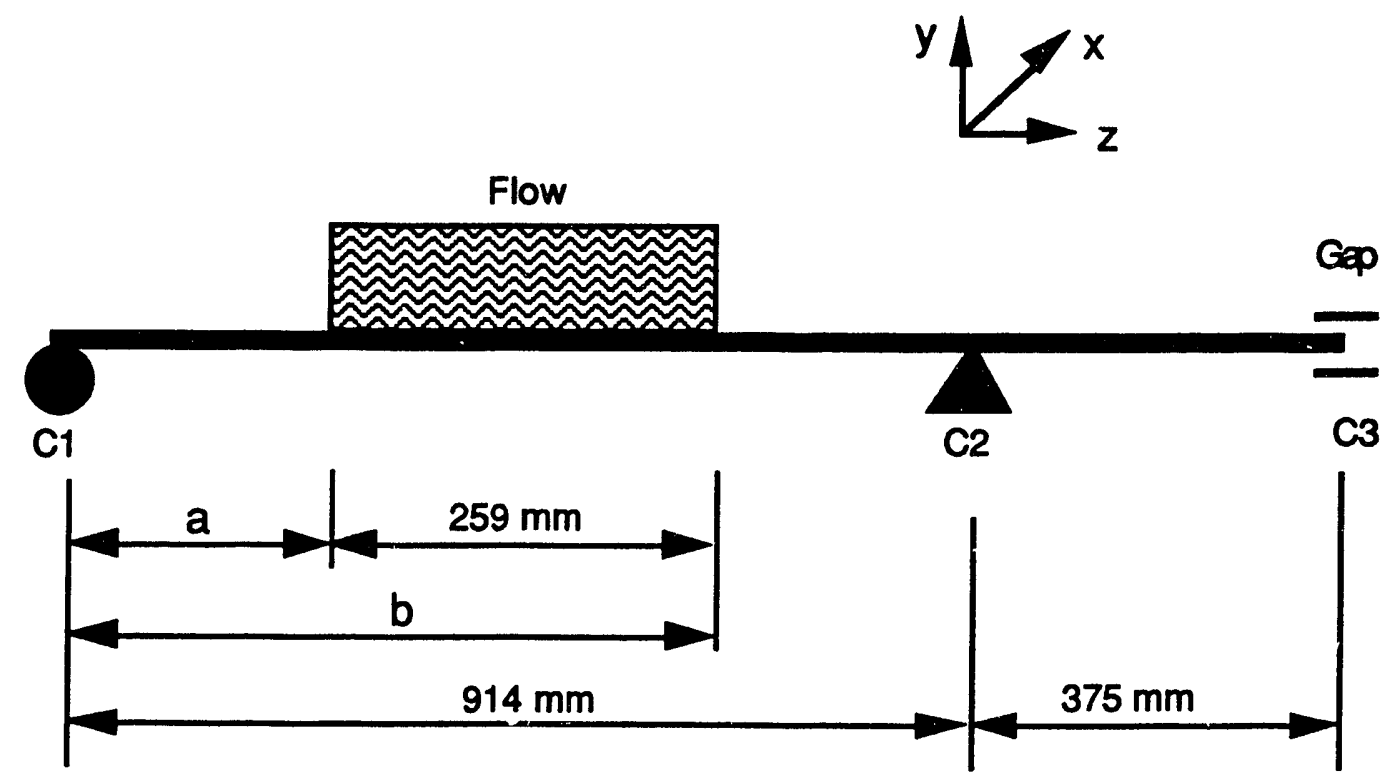

Fig. 2. Schematic of tube and supports (C1 and C2) in crossflow 


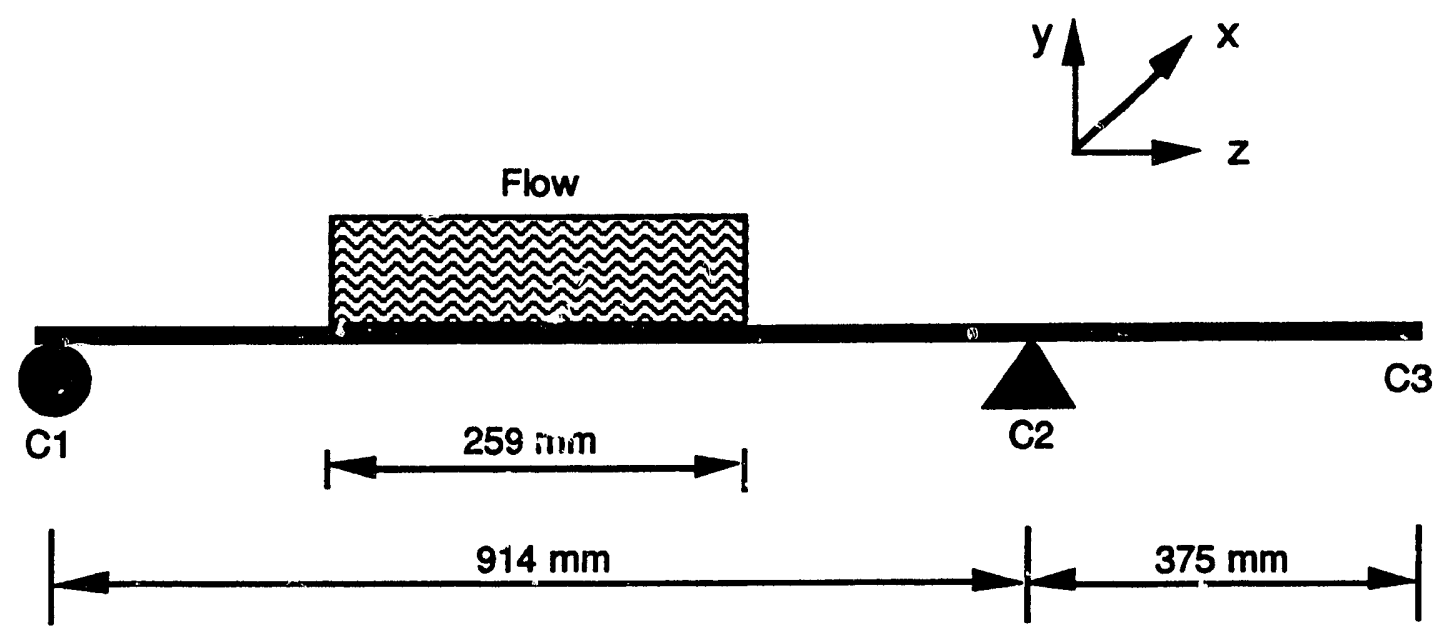

Fig. 3a. Schematic of tube with supports $C 1$ and $C 2$, and right end free

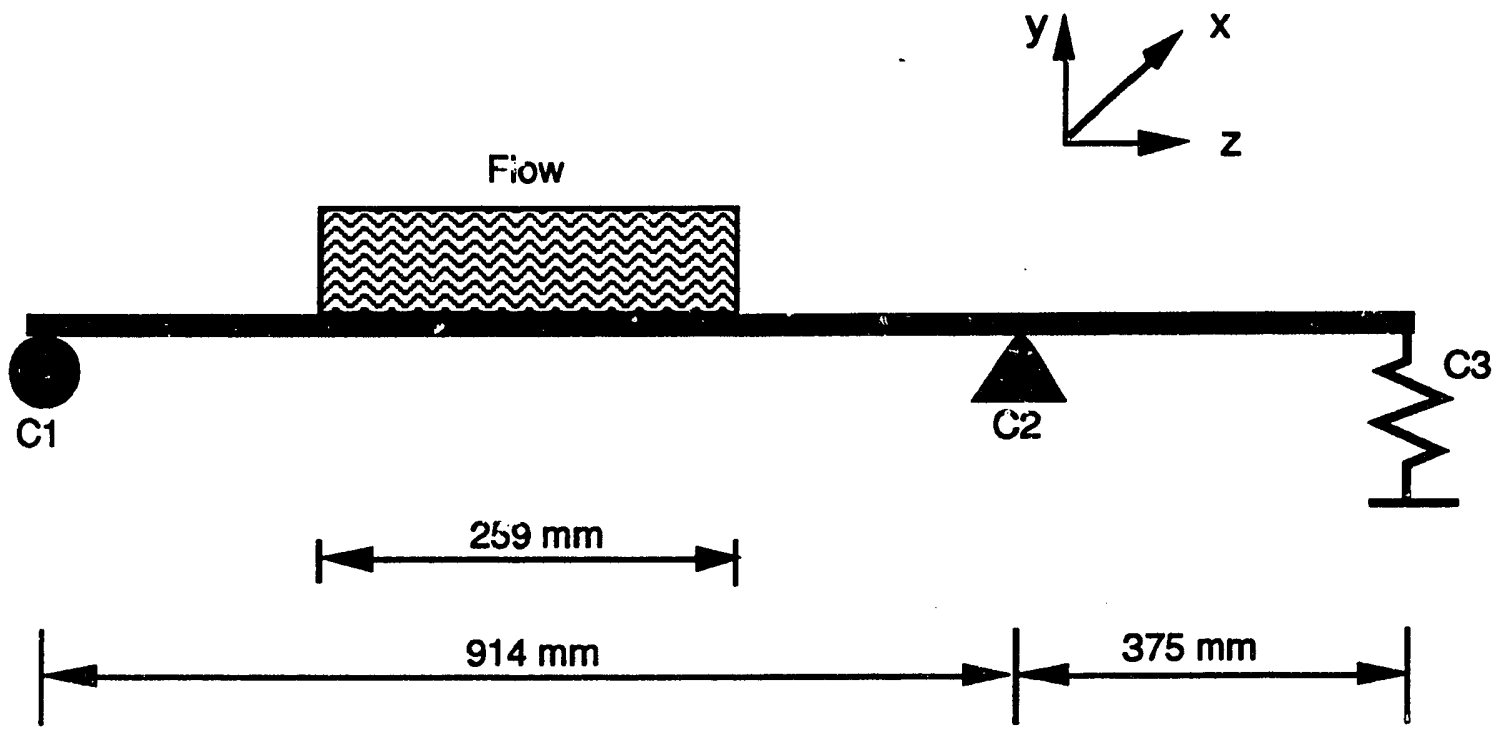

Fig. 3b. Schematic of tube with supports $C 1$ and C2, and right end supported by a spring 
These two models of tube vibration can be analyzed in two different time regions. For Model 1, if we assume that during the time interval $0 \leq t \leq t_{s}$, tube displacements at C3 are within the stop limits $-e_{2}<u(\ell, t)<e_{1}$. The solutions of tube vibration (here considered only in the $x$ direction) by the normal-mode method can be described as

$$
\left.\begin{array}{l}
u(\xi, t)=\sum_{n=1}^{\infty} a_{1 n}(t) \varphi_{1 n}(\xi) \\
\dot{u}(\xi, t)=\sum_{n=1}^{\infty} \dot{a}_{1 n}(t) \varphi_{1 n}(\xi)
\end{array}\right\} \quad \begin{aligned}
& 0<t<t_{s}, \\
&
\end{aligned}
$$

where $\varphi_{1 \mathrm{n}}(\xi)$ are the normal modes of Model 1 (see Appendix), and $\xi=z / \ell$. At time $t=t_{s}$, the right end of the tube strikes the stop and it becomes Model 2, the solutions of the tube vibration of Model 2 by the normal-mode method are

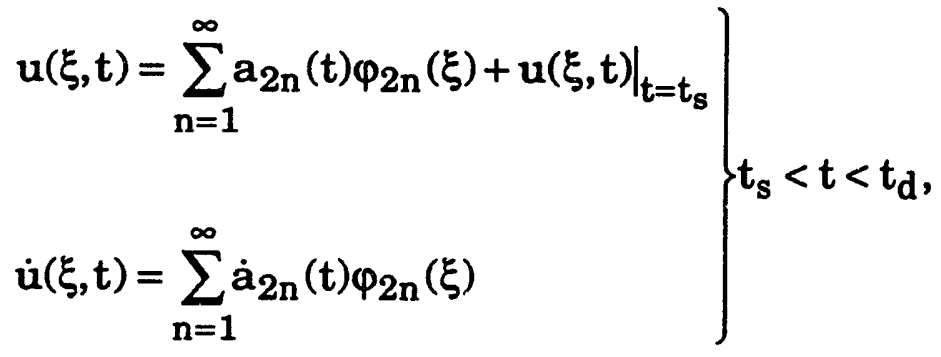

where $\varphi_{2 n}(\xi)$ are the normal modes of Model 2 (see Appendix).

The flow-velocity distribution in Fig. 2 can be defined as

$$
\begin{aligned}
& \psi(\xi)= \begin{cases}0 & 0<\xi<\xi_{\mathrm{a}} \\
1 & \xi_{\mathrm{a}}<\xi<\xi_{\mathrm{b}} \\
0 & \xi_{\mathrm{b}}<\xi<1\end{cases} \\
& \xi_{\mathrm{a}}=\mathrm{a} / \ell, \quad \xi_{\mathrm{b}}=\mathrm{b} / \ell .
\end{aligned}
$$

Therefore, the force coefficients $\alpha_{\mathrm{jj}}^{\mathrm{d}}$ and $\alpha_{\mathrm{jj}}^{\mathrm{e}}$ will be

$$
\begin{aligned}
& \alpha_{\mathrm{jj}}^{\mathrm{d}}=\int_{0}^{1} \alpha_{\mathrm{jj}}^{\prime} \varphi^{2}(\xi) \psi^{2}(\xi) \mathrm{d} \xi=\alpha_{\mathrm{jj}}^{\prime} \int_{0}^{1} \varphi^{2}(\xi) \psi^{2}(\xi) \mathrm{d} \xi \\
& \alpha_{\mathrm{jj}}^{\mathrm{e}}=\int_{0}^{1} \alpha_{\mathrm{jj}}^{\prime \prime} \varphi^{2}(\xi) \psi^{2}(\xi) \mathrm{d} \xi=\alpha_{\mathrm{jj}}^{\prime \prime} \int_{0}^{1} \varphi^{2}(\xi) \psi^{2}(\xi) \mathrm{d} \xi,
\end{aligned}
$$




$$
\varphi(\xi)= \begin{cases}\varphi_{1 n}(\xi) & 0<t<t_{s} \\ \varphi_{2 n}(\xi) & t_{s}<t<t_{d},\end{cases}
$$

where $\alpha_{\mathrm{jj}}^{\prime}$ and $\alpha_{\mathrm{jj}}^{\prime \prime}$ are fluid-damping and fluid-stiffness coefficients, which are functions of reduced flow velocity $U_{r}$.

\section{Numerical Results and Discussion}

A two-span flexible tube with one intermediate support and one end baffle plate (TSP), schematically shown in Fig. 2 , is considered in the simulations. This was the tube row tested by Chen et al. 1 The tube in Fig. 2 is brass, with a $1.59 \mathrm{~cm}$ outside diameter, $1.59 \mathrm{~mm}$ wall thickness, and $131.8 \mathrm{~cm}$ length. The span between $\mathrm{C} 1$ and $\mathrm{C} 2$ is $91.4 \mathrm{~cm}$. The overhung portion of the tube between $\mathrm{C} 2$ and $\mathrm{C} 3$ is $37.5 \mathrm{~cm}$. The tube is submerged in fluid but subjected to flow at the middle portion only. The portion subjected to flow is $25.9 \mathrm{~cm}$ in length and lies between C1 and C2.

The diametral clearance (gap) between the tube and the TSP at C3 is $2.54 \mathrm{~mm}$ in all of the simulations, in order to study the specific phenomenon of symmetric clearance. It is noted that a symmetric clearance makes it easier to interpret the possible chaotic tube motion induced by fluidelastic instability.

Impact stiffness is an important parameter when considering the chaotic motion with a bilinear model of loosely supported tubes. It is expected that response characteristics depend on the impact stiffness, which is a function of support geometries and surrounding fluid. A study will be performed to understand the detailed characteristics. In this study, a reasonable value, $\mathrm{K}_{\mathrm{c}}=$ $10^{7} \mathrm{~N} / \mathrm{m}$, was used in the normal modes of Model 2 (see Eq. 11 in Section 3, and also Eq. 18 in Ref. 26) throughout our simulation.

The loosely supported tube shown in Fig. 2 is a multiple-degree-of-freedom system. The natural frequency of the $n$-th mode for a uniformly submerged tube in water can be expressed as

$$
f_{n}=\frac{k_{n}^{2}}{2 \pi \ell^{2}} \sqrt{\frac{E I}{m_{j}\left(1+\gamma_{j} \alpha_{j j}\right)}},
$$

where $\mathrm{E}$ is the modulus of elasticity (in our case, $\mathrm{E}=15.786 \times 10^{-6} \mathrm{lb} / \mathrm{in} .{ }^{2}$ ); $\mathrm{I}$ is the area moment of inertia of the cross section about the neutral axis (tube 
parameters: $R=0.016 \mathrm{~m}, \mathrm{e}=0.00159 \mathrm{~m}$ ); $\ell$ is tube length; $\mathrm{m}_{\mathrm{j}}$ is the mass per unit length; $\gamma_{j}=\rho \pi R^{2} / m_{j} ; \rho$ is the density of water; $\alpha_{j j}$ is the added-mass coefficient (in our case, $\mathrm{P} / \mathrm{D}=1.33, \mathrm{j}=1, \alpha_{11}=1.113$ ); and $\mathrm{k}_{\mathrm{n}}$ is a dimensionless parameter that is related to the mode numbers and boundary conditions. In our case $k_{n}$ can be calculated from the characteristic equations according to Models 1 and 2 described in Section 3 and in Ref. 26.

Table 1 shows the calculated natural frequencies of the first 10 modes for both Models 1 and 2 in water and the suggested time-integration steps required during simulations. As verified in a previous study, 2610 modes (covering a frequency range of $0-1700 \mathrm{~Hz}$ ) give sufficient accuracy for our case. Therefore, 10 modes were used throughout, and the time-integration step for 10 modes was taken to be $\Delta t=0.0001 \mathrm{~s}$ to ensure the accuracy of simulations.

The computations were carried out on a Sun workstation computer. Integration of the equations of motion was done using closed-form solution. The initial conditions of tube motion in our case were taken as follows: $a_{11}(0)=0$; $\dot{a}_{11}(0)=0.065$; and $a_{1 n}(0)=a_{1 n}(0)=0, n \geq 2$. Numerical integrations were run for a relatively long fixed time to ensure that transient effects have died out before the outputs are examined. In our case, this took less than $0.1 \mathrm{~s}$. Then, time histories, phase portraits, Poincaré maps, and bifurcation diagrams were recorded and drawn.

\subsection{Critical Flow Velocity}

The relation of the reduced flow velocity and the mean flow velocity, as described in Eq. 8, is dependent on oscillation frequency $\omega$, which depends on the reduced flow velocity $U_{r}$ and the coefficients $\alpha_{j \mathrm{j}}^{e}$ (see Eq. 9). Consider Model 1, which domains the tube motion: $\omega_{1}$ can be iterated from Eqs. 8 and 9, and then, the relation of the reduced flow velocity and the mean flow velocity can be obtained as shown in Fig. 4, which is almost linear.

The critical flow velucity can be determined by setting the damping term equal to zero, i.e., 
Table 1. Calculated natural frequencies of a tube

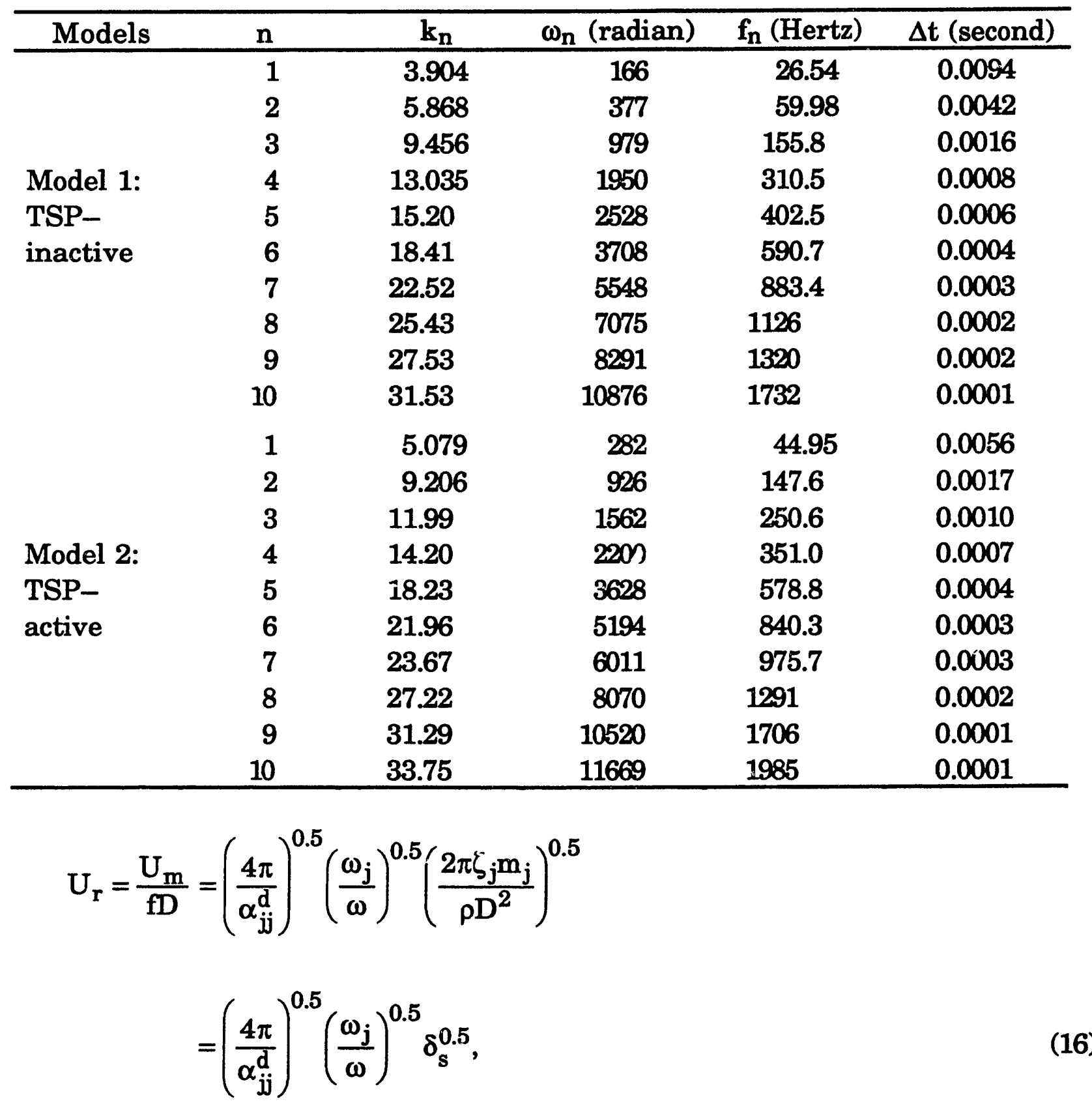

where $\delta_{\mathrm{s}}$ is mass-damping parameter, in this case $\delta_{\mathrm{s}}=0.3$. The critical flow velocities are given in Fig. 5, where they are plotted as a function of $\delta_{\mathrm{s}}$. The stable and unstable regions can readily be observed in Fig. 5 . It should be noted that when the flow velocity is increased to the critical value $U_{r}=4.15$, instability of tube motion occurs. As the flow velocity is increased further, the tube executes largeamplitude oscillations in the unstable zone. When the flow velocity reaches the second critical value $U_{r}=8.42$, the tube enters the stable zone; however, the tube may not regain stability because of nonlinear effects. 


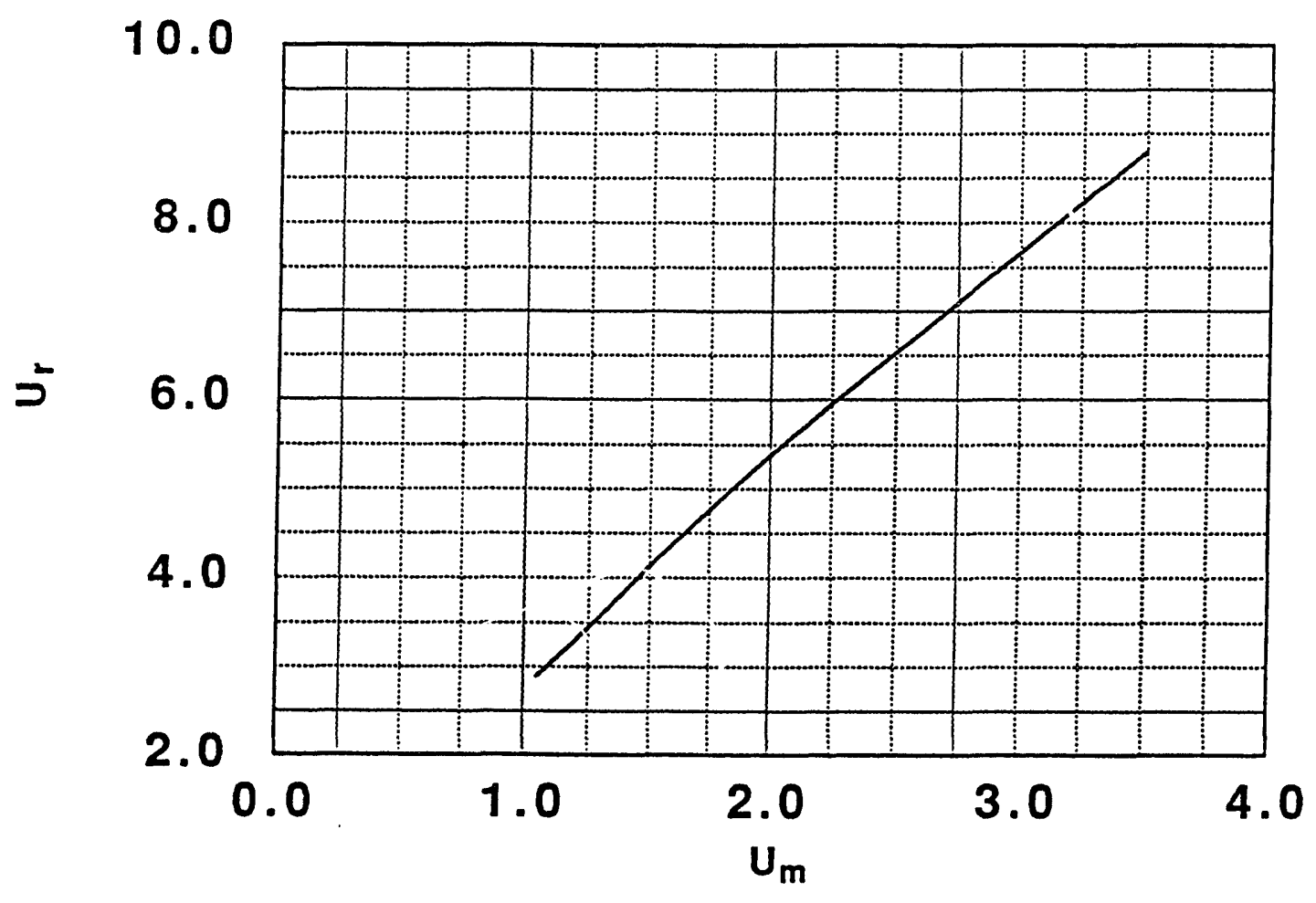

Fig. 4. Relationship of reduced flow velocity and mean flow velocity when mass-damping parameter is equal to 0.3 in Model 1

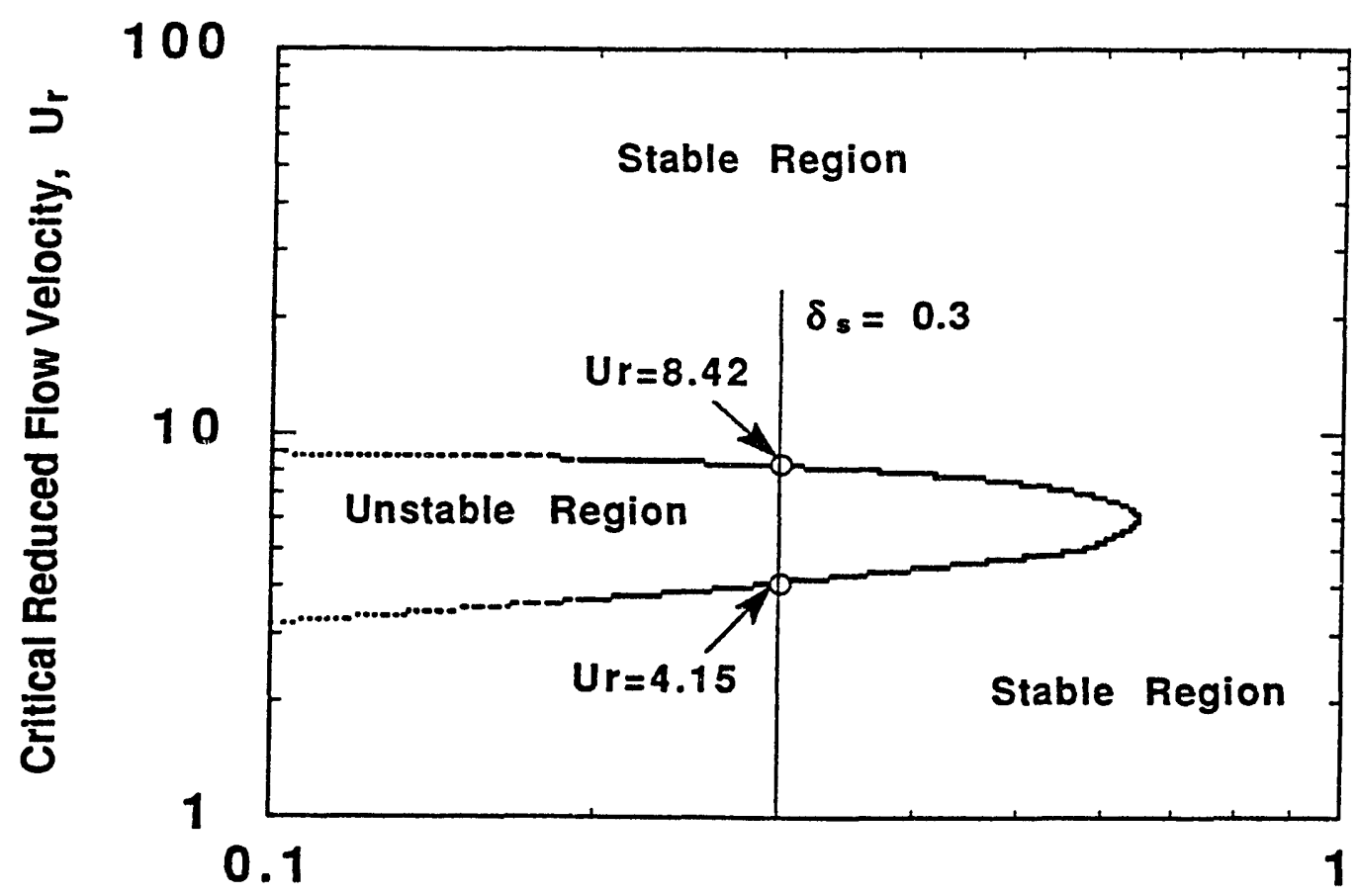

Mass-Damping Parameter, $\delta$ s

Fig. 5. Stability map 
According to Eqs. 6, system damping depends on flow velocity and fluid force coefficients, namely

$$
\zeta=\left(2 \zeta_{j} \omega_{j}-\frac{\gamma_{j}}{\pi^{3}} U_{r}^{2} \omega \alpha_{j j}^{d}\right) /(2 \omega)
$$

or

$$
\zeta=\left(2 \zeta_{j} \omega_{j}-\frac{\gamma_{j}}{\pi R^{2}} \frac{U_{m}^{2}}{\omega} \alpha_{j j}^{d}\right) /(2 \omega),
$$

where fluid force coefficients are also functions of flow velocity and $\omega$. When the flow velocity is high enough, system damping may become negative and tube motion becomes unstable. Figures 6 and 7 show system damping as functions of reduced flow velocity and mean flow velocity for Model 1 . We can find that the critical reduced flow velocity $U_{\mathrm{r}}=4.15$ and the critical mean flow velocity $U_{\mathrm{m}}=$ $1.52 \mathrm{~m} / \mathrm{s}$, at which damping is equal to zero.

Figure 8 shows a plot of the ratio of RMS tube displacement to tube diameter vs. flow velocity. Tube response characteristics here include regions of lowamplitude oscillation and instability of the TSP-inactive mode. In the lowamplitude-oscillation region (for flow velocity lower than the critical flow velocity, namely, $U_{m}<152 \mathrm{~m} / \mathrm{s}$ ), tube motion is small and the tube responds in the TSPinactive mode. This is a stable region and because the system damping is positive, the simulated tube oscillation will die out when the run time is adequate.

In the instability region of the TSP-inactive mode, as the flow velocity increases to the critical flow velocity, the TSP-inactive mode becomes unstable. Once the tube loses its stability, large-amplitude oscillations occur and the tube impacts the TSP. Obviously, the number of impacts during a fixed time interval will increase with the flow velocity in this instability region. When the flow velocity reaches a certain value $\left(U_{m}=1.8 \mathrm{~m} / \mathrm{s}\right)$, the tube impacts the TSP in every oscillation cycle. Therefore, the maximum peak-to-peak displacement at the TSP is that of the diametral clearance. In this range of flow velocity, tube displacement is almost independent of flow velocity because the motion shifts into a stable TSP-active mode when a tube regularly impacts the TSP and the number of tubes impacting the TSP per cycle of oscillation is equal to 2; it appears to be a periodic oscillation. We should note that the most interesting range is from where the tube begins to lose its instability $\left(U_{m}=1.52 \mathrm{~m} / \mathrm{s}\right)$ to where it reaches a periodic oscillation with regular impacting $\left(U_{m}=1.8 \mathrm{~m} / \mathrm{s}\right)$. In this range, the number of impacts is a function of flow velocity and initial conditions. Any 


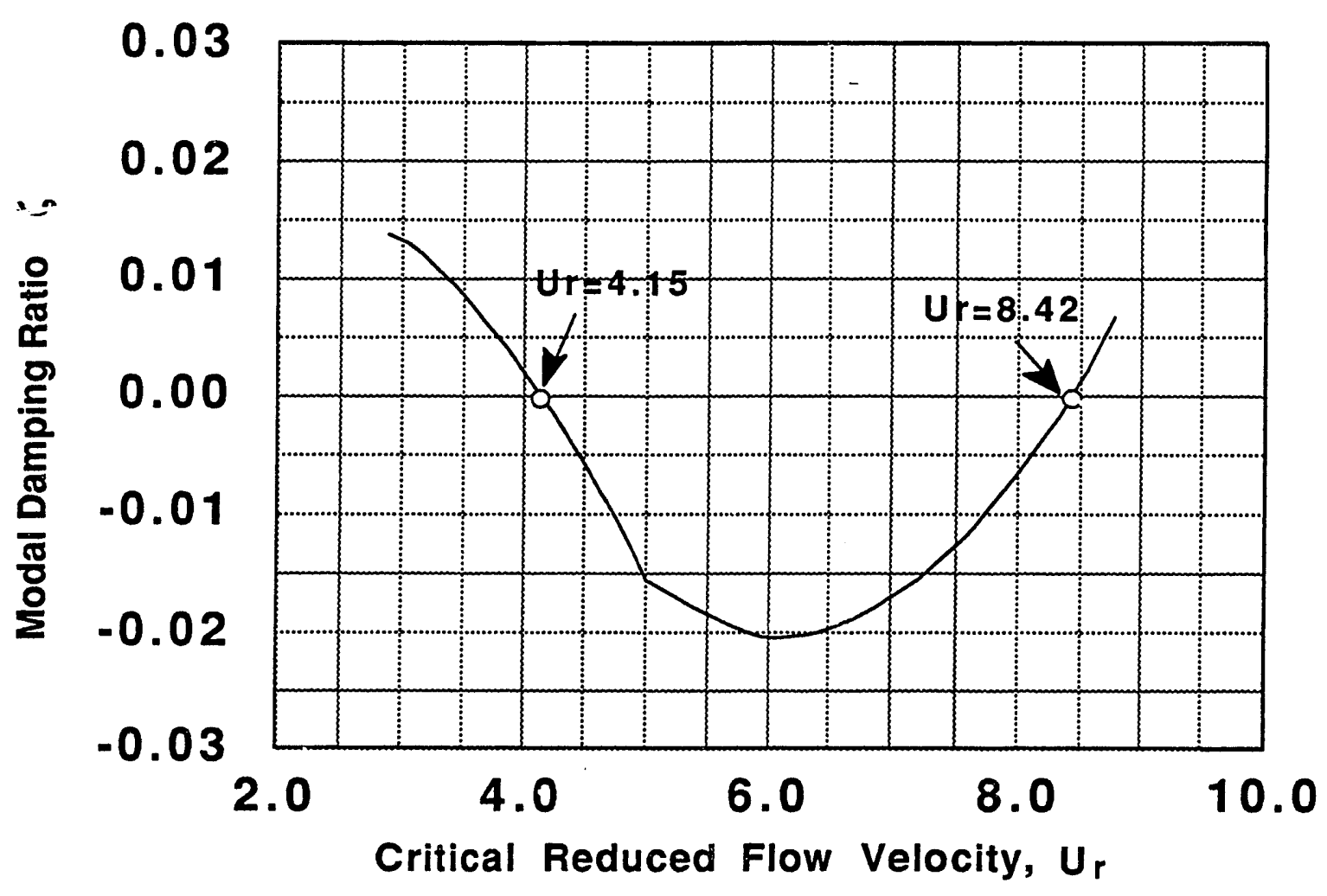

Fig. 6. System damping vs. reduced flow velocity

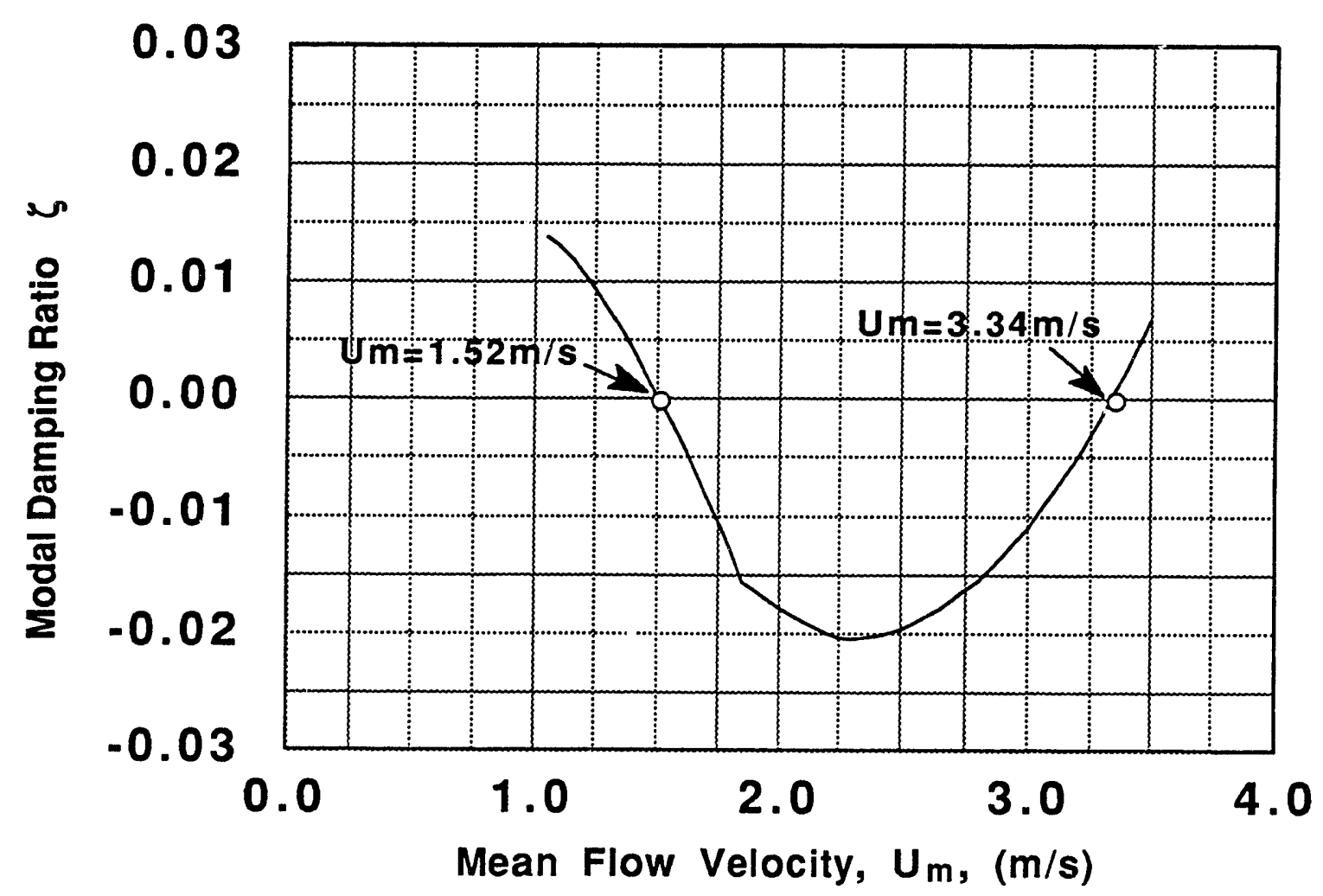

Fig. 7. System damping vs. mean flow velocity 


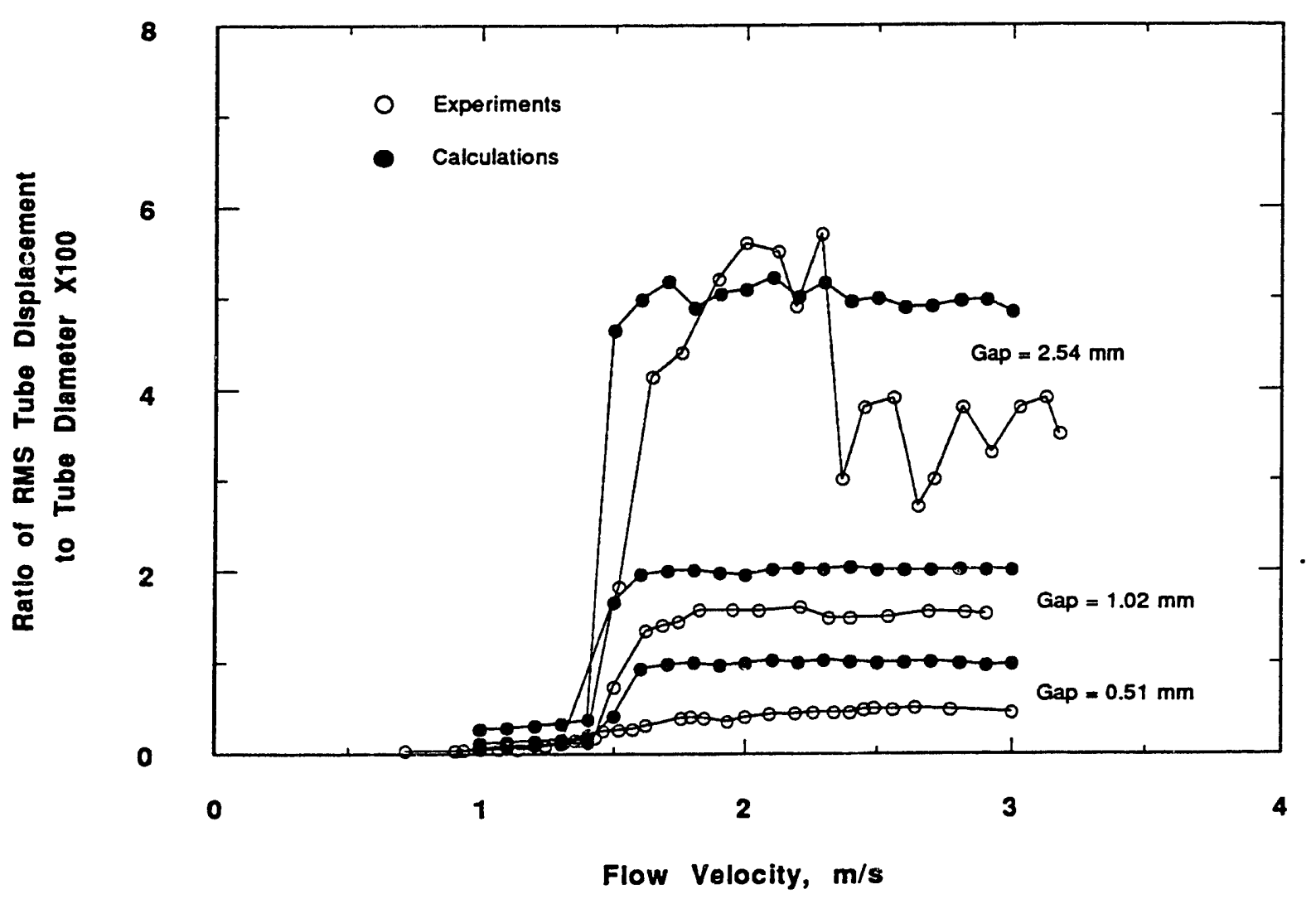

Fig. 8. RMS tube displacement as a function of flow velocity for various diametral gaps

possible chaotic motion will occur in this range. We note that this range is very sensitive to geometry of clearances at the TSP and contact stiffness between tube and TSP. Because the effects of those parameters are extremely complicated, we will not discuss them in this report. A fixed and symmetric clearance $(e=$ $2.54 \mathrm{~mm})$ and a fixed impact stiffness $\left(K_{c}=10^{7} \mathrm{~N} / \mathrm{m}\right)$ were applied in our simulation in this work.

From Fig. 8 we see that the results from the simulation by the bilinear fluidelastic model agree reasonably well with the experimental data of Chen et al. 1 We also note that in Fig. 8, flow velocity in both experiment and simulation is up to $3 \mathrm{~m} / \mathrm{s}$ because once flow velocity exceeds some values, a TSP-active mode becomes unstable and other nonlinear effects become important. Therefore, the bilinear model, which does not include those nonlinear effects, is not applicable to the instability region associated with the TSP-active mode. This means that even when the flow velocity is increased to the second critical flow velocity (see Fig. 5), the tube will not regain stability. In fact, it was obiserved in the previous experiments that with further increase in flow velocity, the tube becomes unstable in the TSP-active mode, and oscillation amplitude can increase significantly. 
In summary, when flow velocity is lower than critical flow velocity, tube motion is stable; when flow velocity exceeds critical flow velocity, the tube will lose its stability and begin an amplified oscillation, namely, it will yield a Hopf bifurcation. If the tube impacts the TSP irregularly in the instability region, tube motion depends on flow velocity and other parameters and chaotic motion may occur. If the tube impacts the TSP regularly after flow velocity exceeds some value in the instability region, tube motion is almost independent of flow velocity and a periodic oscillation will occur with a fixed amplitude equal to the diametral clearance. When flow velocity is increased further, the TSP-active mode becomes unstable and a significant large-amplitude tube oscillation may occur. We will not discuss the effects of this range in this report.

\subsection{Bifurcation Diagram}

A widely used technique for examining the prechaotic or postchaotic changes in a dynamic system under parameter variations is the bifurcation diagram, from which we may find a route to chaos, namely a route from periodic to chaotic motions through parameter changes. With fast computers available, it is easy and helpful to vary the control parameter to obtain a bifurcation diagram. From this diagram, we can see if the system has steady or periodic or chaotic behavior for some continuous range of flow velocity in order to obtain a full understanding of system dynamics. In this way, we can have confidence in deciding more definitely whether the system becomes chaotic. Also, we can observe and pinpoint sudden changes in system behavior. Both the control parameter and the output signal must be carefully chosen to ensure that they can provide sufficient information.

In our case, flow velocity was chosen as the control parameter and tube displacement as the output signal. The difficulty is in determining the locations of the triggering signal and output signal to produce an easily interpreted bifurcation diagram. On examining many run results, the velocity of tube motion at location C3 $(\xi=1.0)$ is taken as the triggering signal, and the displacement at locations $\xi=1.0$ and $\xi=0.9$ is taken as output signal. When the triggering signal is equal to zero, $\dot{u}(1.0, t)=0$, and tube displacement at $\xi=1.0$ is positive, $u(1.0, t)>0$, the values of $u(1.0, t)$ and $u(0.9, t)$ are recorded. By slow variation of flow velocity, the bifurcation diagrams are produced as shown in Figs. 9 and 10, corresponding to $\xi=0.9$ and $\xi=1.0$. In calculating various flow velocities, the initial conditions $\mathrm{a}_{11}(0)=0, \dot{\mathrm{a}}_{11}(0)=0.065$ and $\mathrm{a}_{1 \mathrm{n}}(0)=\dot{\mathrm{u}}_{1 \mathrm{n}}=0, \mathrm{n} \geq 2$ were utilized, as stated previously. With this specific system and parameters, it has been proved in our calculations that those initial conditions can reduce the transient time of tube motion in the calculations. 


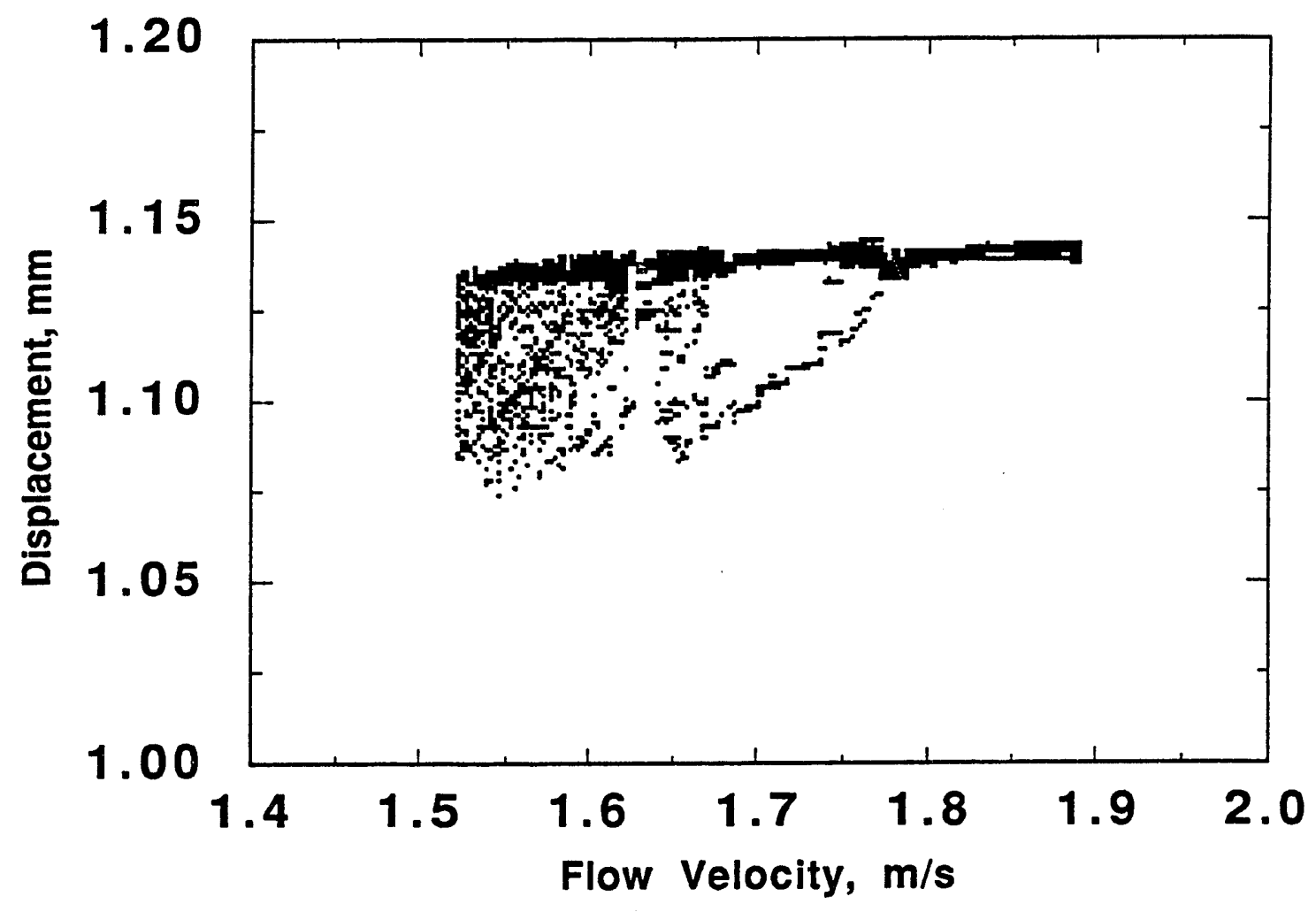

Fig. 9. Bifurcation diagram $(\xi=0.9)$

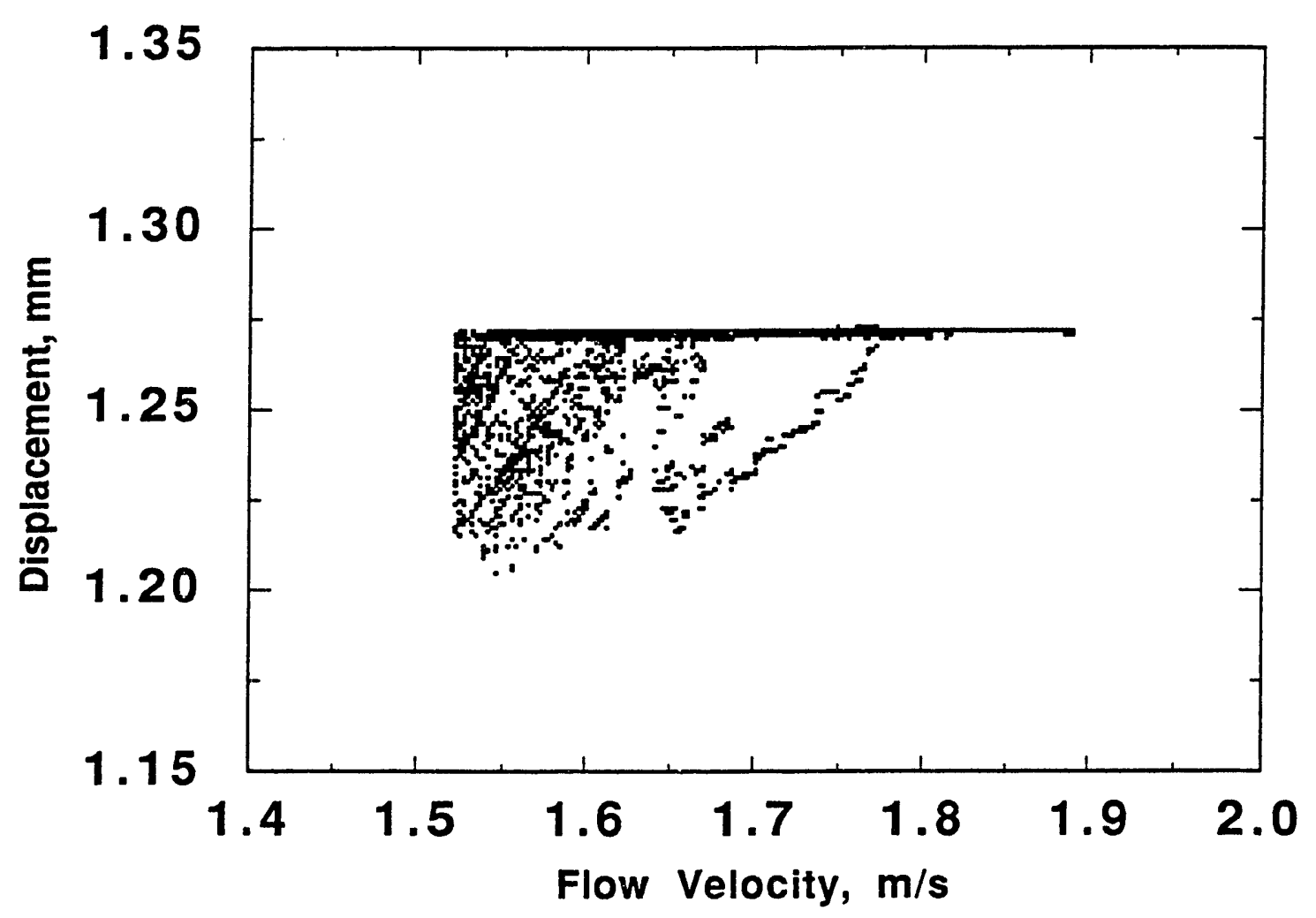

Fig. 10. Bifurcation diagram $(\xi=1.0)$ 
In Figs. 9 and 10, it is clear that for flow velocity less than the critical flow velocity $\left(U_{\mathrm{Ti}}=1.52 \mathrm{~m} / \mathrm{s}\right.$ ), all oscillations die out as time increases; when flow velocity reaches the critical value, there is a jump of displacement (i.e., the Hopf bifurcation occurs). When the tube loses its stability and the tube impacts the TSP, a chaotic motion occurs (see Figs. 9 and 10 ). As flow velocity increases $\left(U_{m} \geq\right.$ $1.67 \mathrm{~m} / \mathrm{s}$ ), the number of impacts increase in what appears to be quasiperiodic vibration. As flow velocity further increases to $U_{m}=1.78 \mathrm{~m} / \mathrm{s}$, the tube impacts the TSP regularly in a harmonic periodic vibration. This periodic region continues as flow velocity increases until the TSP-active mode becomes unstable. Therefore, in the instability region (where system damping is negative), the route to chaos can be described as that when the flow velocity is larger than $U_{m}=1.78$ $\mathrm{m} / \mathrm{s}$, there is a typical periodic vibration; when flow velocity is lower than $U_{m}=$ $1.78 \mathrm{~m} / \mathrm{s}$ but higher than $1.67 \mathrm{~m} / \mathrm{s}$, there is a quasiperiodic vibration; when flow velocity is lower than $U_{m}=1.67 \mathrm{~m} / \mathrm{s}$, the vibrations become chaotic. Obviously, the route to chaos in our system is through a sequence of periodic, quasiperiodic, and chaotic regions within instability of the TSP-inactive mode. It is also noted that in the chaotic region, the motion appears only as a limited-band chaos.

\subsection{Phase Portraits}

From the bifurcation diagram (Figs. 9 and 10) we note that there are several meaningful values of flow velocity in the instability region of the TSP-inactive mode; these correspond to chaos, quasiperiodic, and periodic regions. Therefore, we calculated the time histories and phase flow diagrams at those different flow velocities.

Figure 11 shows displacements, velocity, and phase portraits of tube motion at location of $\xi=1.0$ (C3) with flow velocities of $1.55,1.6,1.7$, and $1.8 \mathrm{~m} / \mathrm{s}$. In those time histories and phase flow diagrams of tube motion, the transient has been eliminated for clarity; only the dynamics of the "steady state" are shown. Because the tube support span is asymmetric and the system is considered as a multipledegree-of-freedom system, 10 modes are utilized to obtain accurate simulations. In Fig. 11a-3, the phase portrait at flow velocity $U_{m}=1.8 \mathrm{~m} / \mathrm{s}$ (periodic region) is not an ellipse (as is that calculated by 1 mode), but a complicated closed circle. At this flow velocity, the tube impacts the TSP twice each cycle (Figs. 11a-1 and a-2), in what appears to be a periodic oscillation that repeats very well. When flow velocity decreases to $U_{m}=1.7 \mathrm{~m} / \mathrm{s}$, the tube impacts the TSP once every two cycles (Figs. $11 \mathrm{~b}-1$ and $\mathrm{b}-2$ ); the phase portrait (Fig. 11b-3) indicates that a perioddoubling bifurcation has occurred, and the motion is clearly of period 2. As flow velocity decreases further, the number of impacts is reduced and the impact period appears to be irregular (see Figs. $11 \mathrm{c}-1$ and $\mathrm{c}-2$ with $U_{\mathrm{m}}=1.6 \mathrm{~m} / \mathrm{s}$, and Figs. $11 \mathrm{~d}-1$ and $\mathrm{d}-2$ with $U_{m}=1.55 \mathrm{~m} / \mathrm{s}$ ). During this flow range, phase portraits 

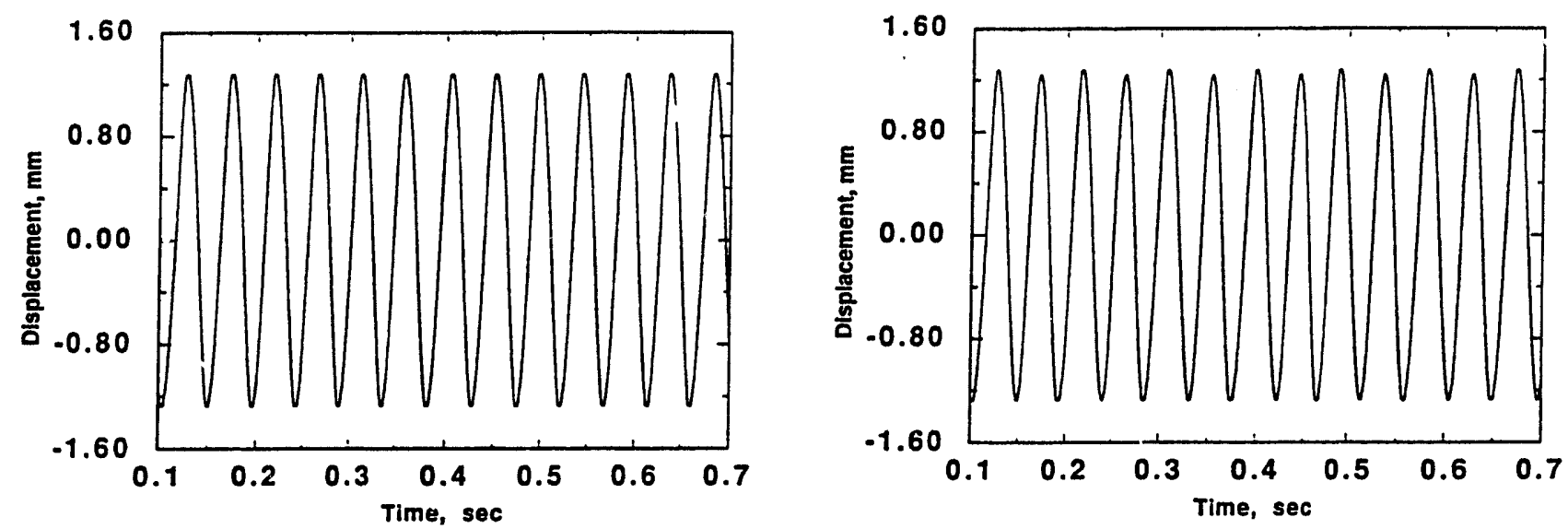

$$
\text { a-1 }
$$

Displacement

b-1
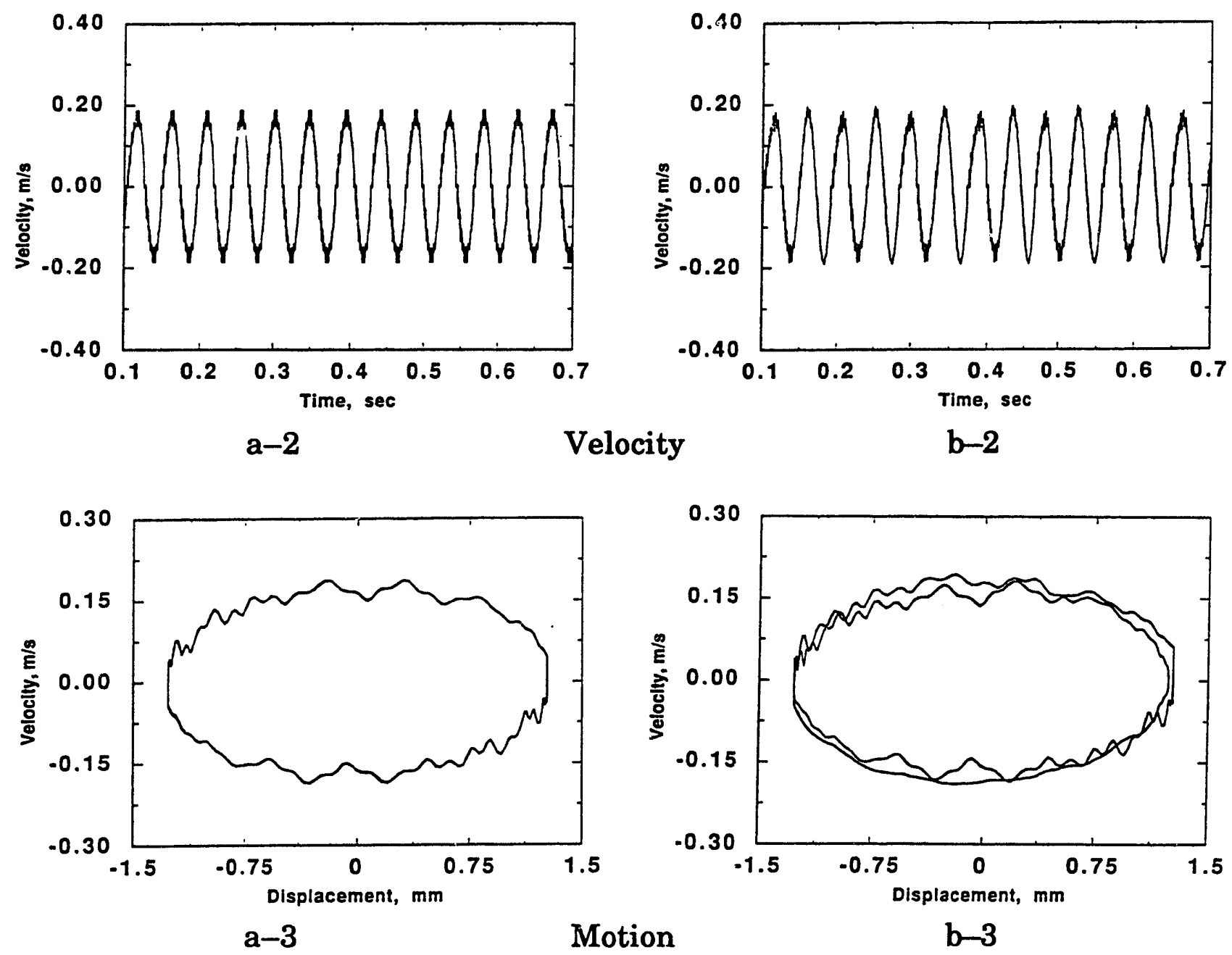

(a) $U_{\mathrm{m}}=1.8 \mathrm{~m} / \mathrm{s}$

(b) $U_{\mathrm{m}}=1.7 \mathrm{~m} / \mathrm{s}$

Fig. 11. Time history of tube displacement, velocity, and motion at $\xi=1.0$ with (a) $U_{m}=1.8 \mathrm{~m} / \mathrm{s}$, (b) $U_{m}=1.7 \mathrm{~m} / \mathrm{s}$, (c) $U_{m}=1.6 \mathrm{~m} / \mathrm{s}$, and (d) $U_{m}=1.55 \mathrm{~m} / \mathrm{s}$ 

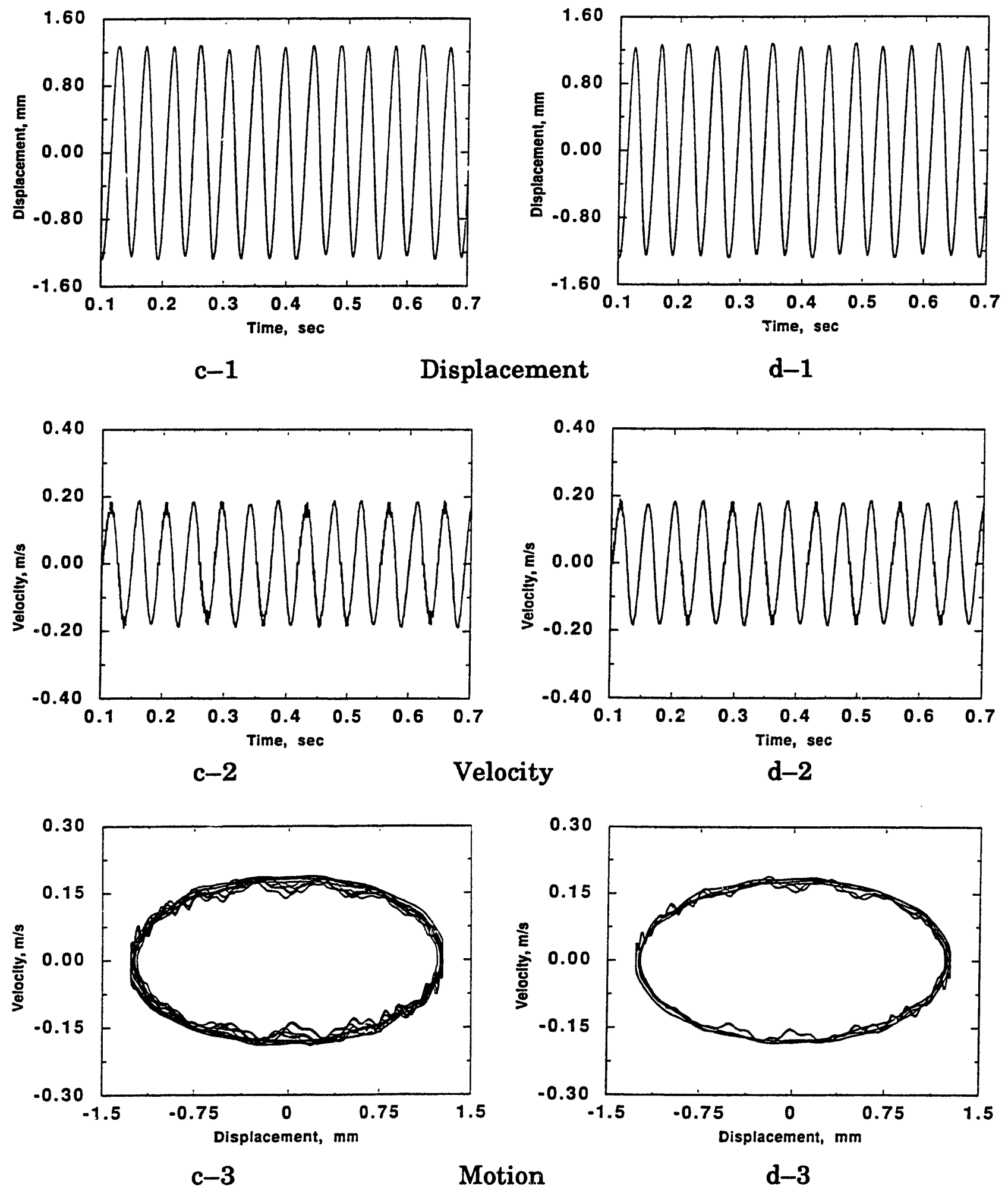

(c) $U_{\mathrm{m}}=1.6 \mathrm{~m} / \mathrm{s}$

(d) $U_{m}=1.55 \mathrm{~m} / \mathrm{s}$

Fig. 11. (Cont'd) 
(Figs. 11c-3 and 11d-3) appear chautic -a kind of limited-band chaos. These chaotic motions apparently depend on the number of impacts during certain cycles, while impacts depend on the flow velocity (values of negative system damping), initial conditions, and other parameters such as clearance and contact stiffness.

Figure 12 shows time histories of tube displacement and velocity, and phase portraits at the location of $\xi=0.8$ with flow velocities equal to $1.55,1.6,1.7$, and $1.8 \mathrm{~m} / \mathrm{s}$. If Fig. 12 is compared with Fig. 11 at the same flow velocity, the phase portraits appear quite different at different locations. In Fig. $12(\xi=0.8)$, phase portraits show a small loop that may be a special characteristic of the motion. When the end of tube (C3) strikes one side of the TSP, the other part of tube (for example, $\xi=0.8$ ) vibrates slightly once before it leaves the TSP and moves to the other side, creating a small cycle.

Figure 13 shows time histories of tube displacement and velocity, together with phase portraits at the location of $\xi=0.4$. Because this location is far from the end of the tube and almost midwray between $\mathrm{C} 1$ and $\mathrm{C2}$, higher modes excited by impacting have less influence or time histories, especially velocity of tube motion, than those at overhung parts of tube (comparing with Fig. 11 [ $\xi=1.0]$ and Fig. 12 $[\xi=0.8]$ ). However, no matter what the location, periodic, doubling periodic, and chaotic motion associated with various flow velocities are almost the same in Figs. 11, 12, and 13.

\subsection{Power Spectral Density}

Power spectra make it possible to distinguish between periodic and chaotic responses. It is known that for a periodic motion, discrete frequencies dominate in the power spectral density, while for a chaotic motion, the power spectrum is a continuous process, although peaks can be observed in this process. Figure 14 shows the power spectral density (PSD) of tube displacements at different flow velocities. It is observed that the fundamental oscillation frequencies at different flow velocities are approximatelv the same, i.e., $f_{1}=22.28 \mathrm{~Hz}$; therefore, a nondimensional frequency $f / f_{1}$ is adopted in Fig. 14 .

Figure 14a shows the PSD of tube displacement at $U_{m}=1.8 \mathrm{~m} / \mathrm{s}$, which appears to be periodic with superharmonic componer $t s, f / f_{1}=1,3,5, \ldots$. This is caused by tube impacting (see Fig. 11-1a; there is a small flat-top of displacement when the tube impacts the TSP and Model 2 is applied).

According to the bifurcation diagrams in Figs. 9 and 10 , from $U_{m}=1.78 \mathrm{~m} / \mathrm{s}$ to $U_{m}=1.65 \mathrm{~m} / \mathrm{s}$, there exists a quasiperiodic motion region. Figures $14 \mathrm{~b}-14 \mathrm{e}$ give 

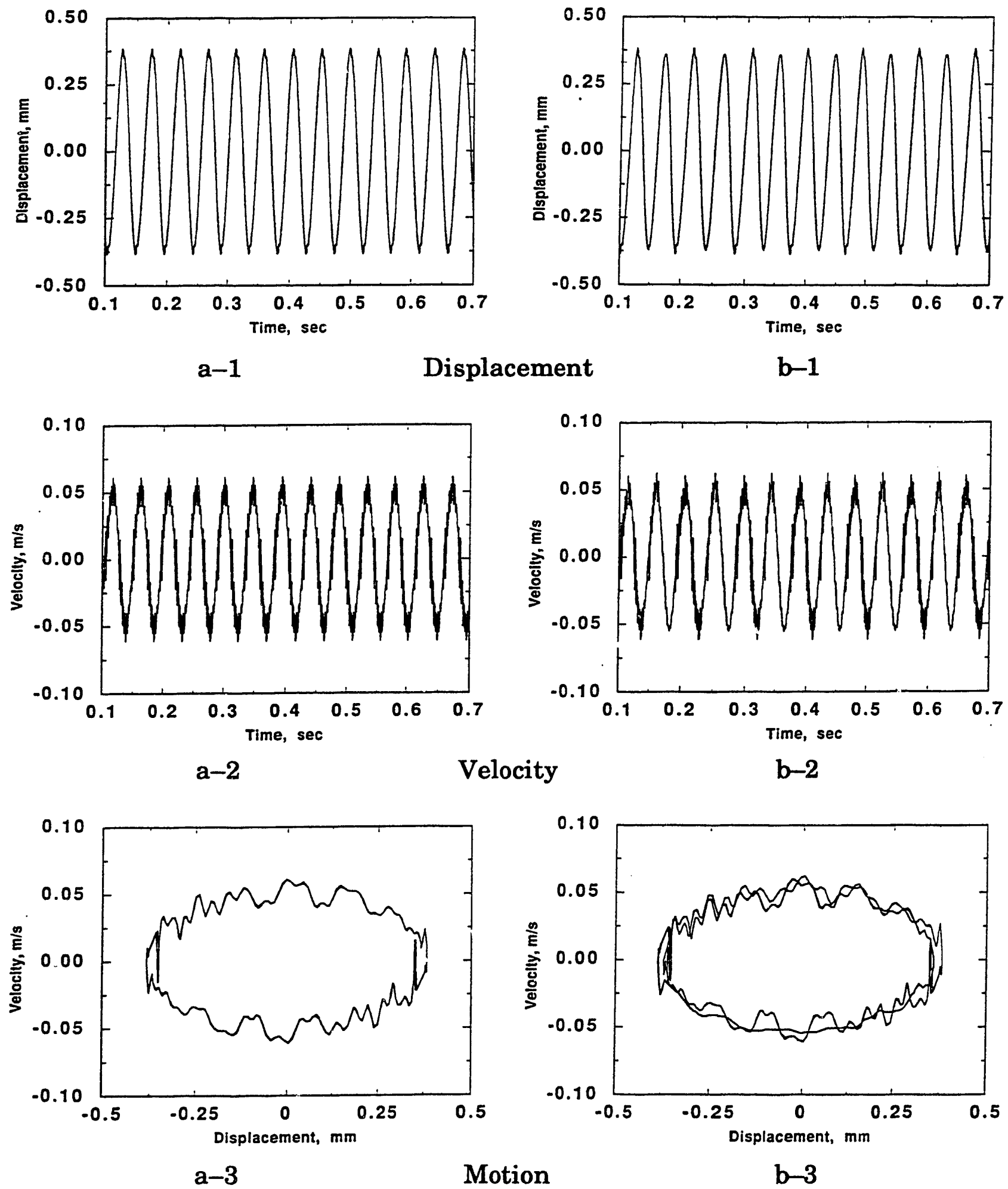

(a) $U_{m}=1.8 \mathrm{~m} / \mathrm{s}$

(b) $\mathrm{U}_{\mathrm{m}}=1.7 \mathrm{~m} / \mathrm{s}$

Fig. 12. Time history of tube displacement, velocity, and motion at $\xi=0.8$ with (a) $U_{m}=1.8 \mathrm{~m} / \mathrm{s}$, (b) $U_{m}=1.7 \mathrm{~m} / \mathrm{s}$, (c) $U_{m}=1.6 \mathrm{~m} / \mathrm{s}$, and (d) $U_{m}=1.55 \mathrm{~m} / \mathrm{s}$ 


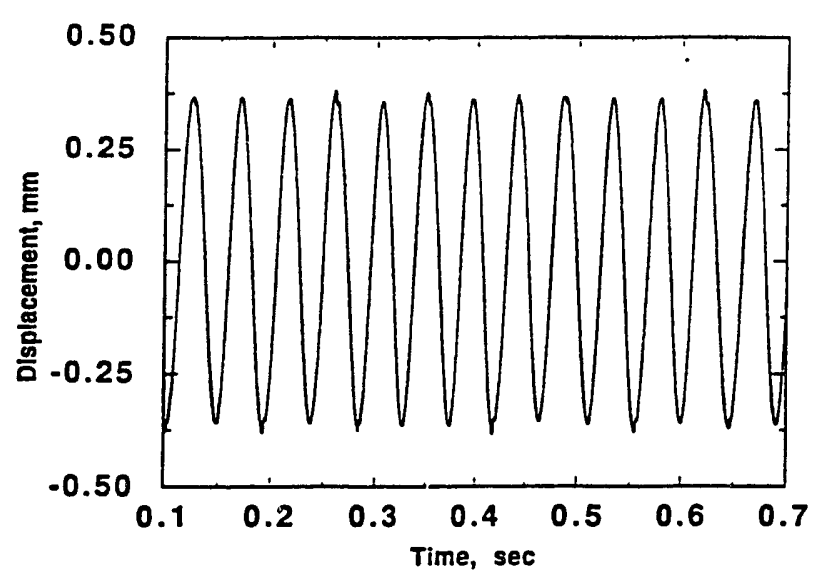

c-1

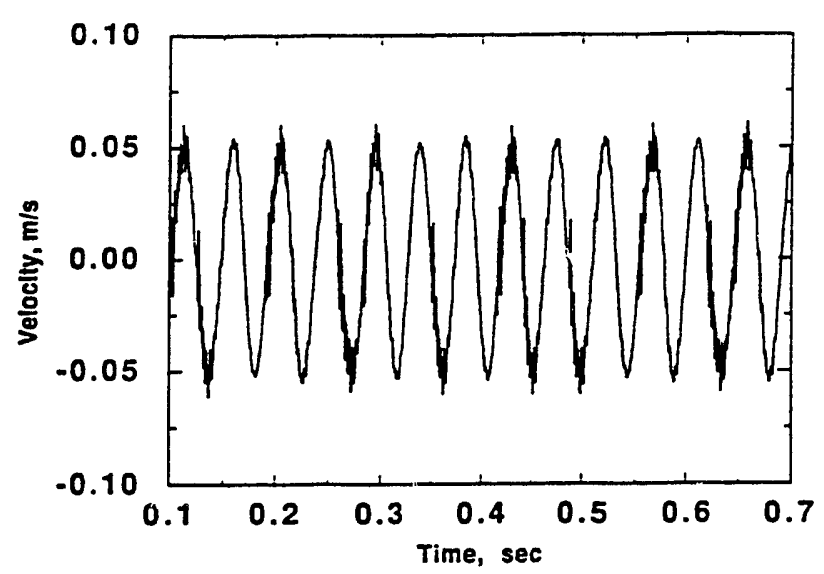

c-2

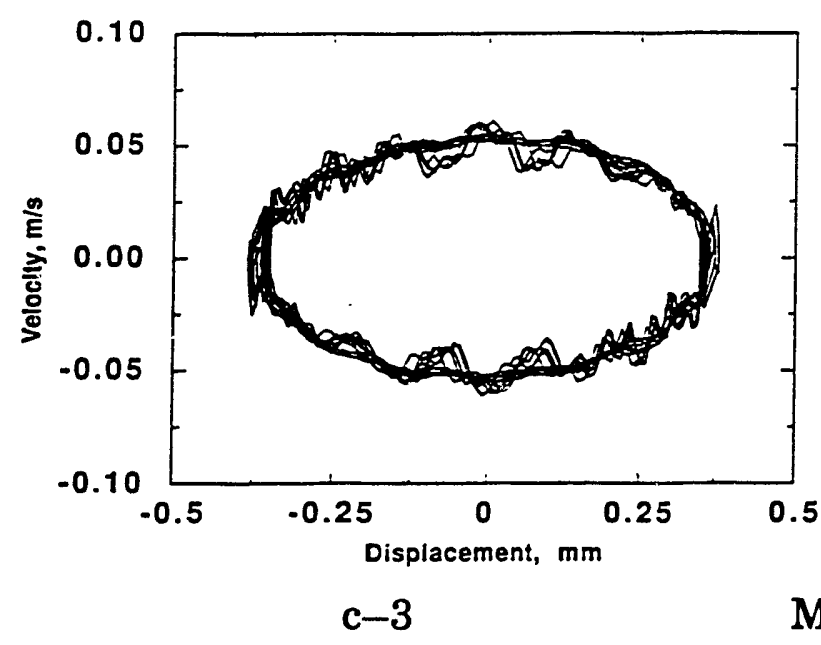

(c) $U_{\mathrm{m}}=1.6 \mathrm{~m} / \mathrm{s}$

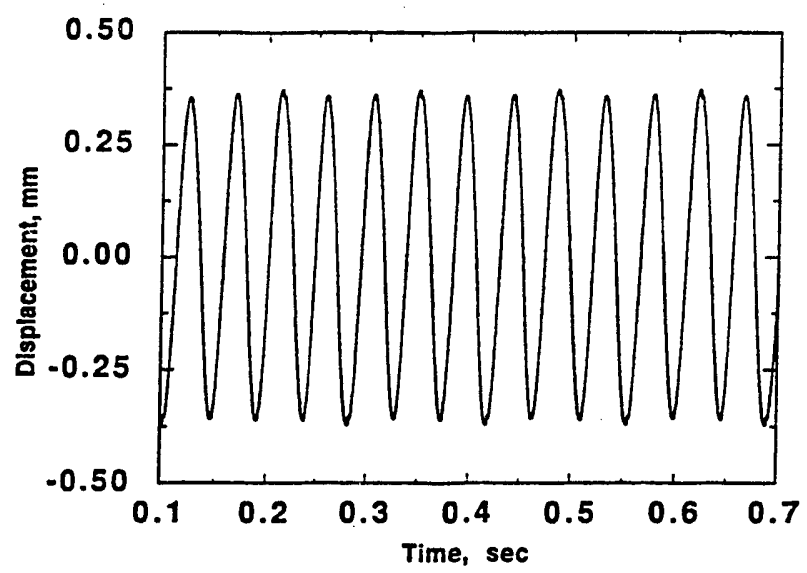

d-1
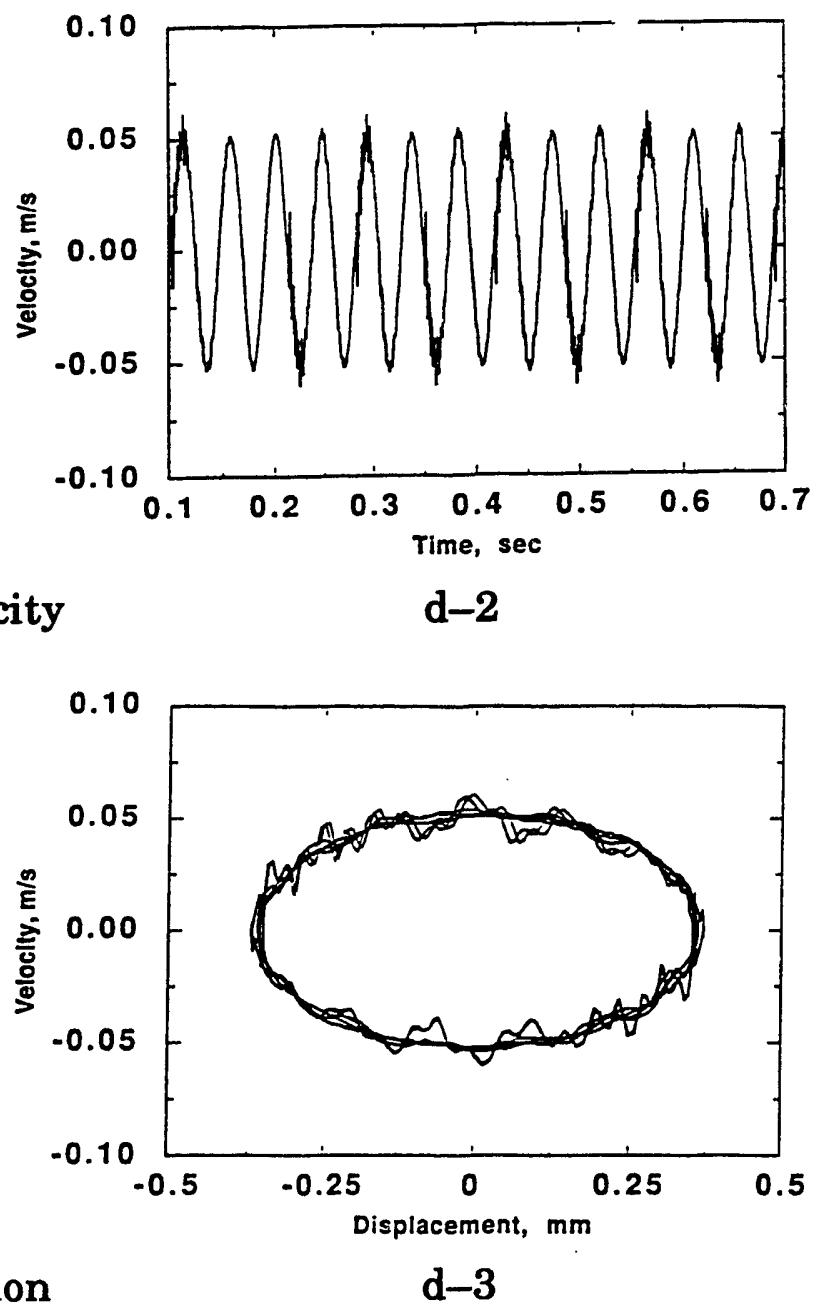

Motion

(d) $U_{m}=1.55 \mathrm{~m} / \mathrm{s}$

Fig. 12. (Cont'd) 

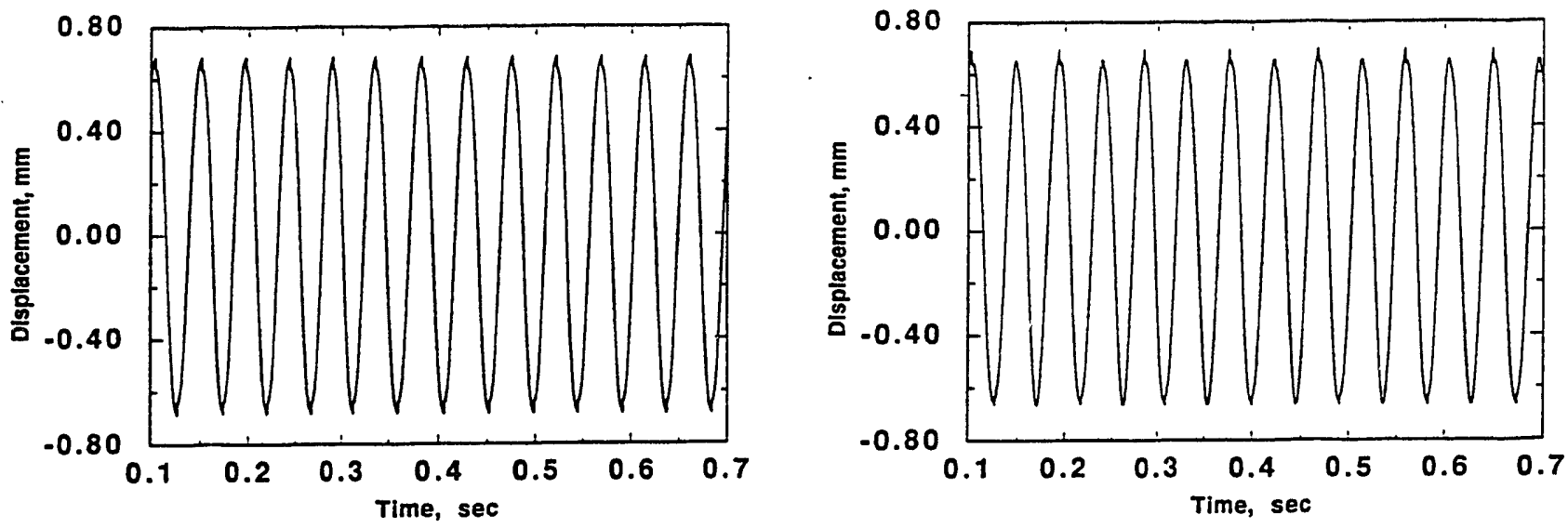

a-1

Displacement

b-1
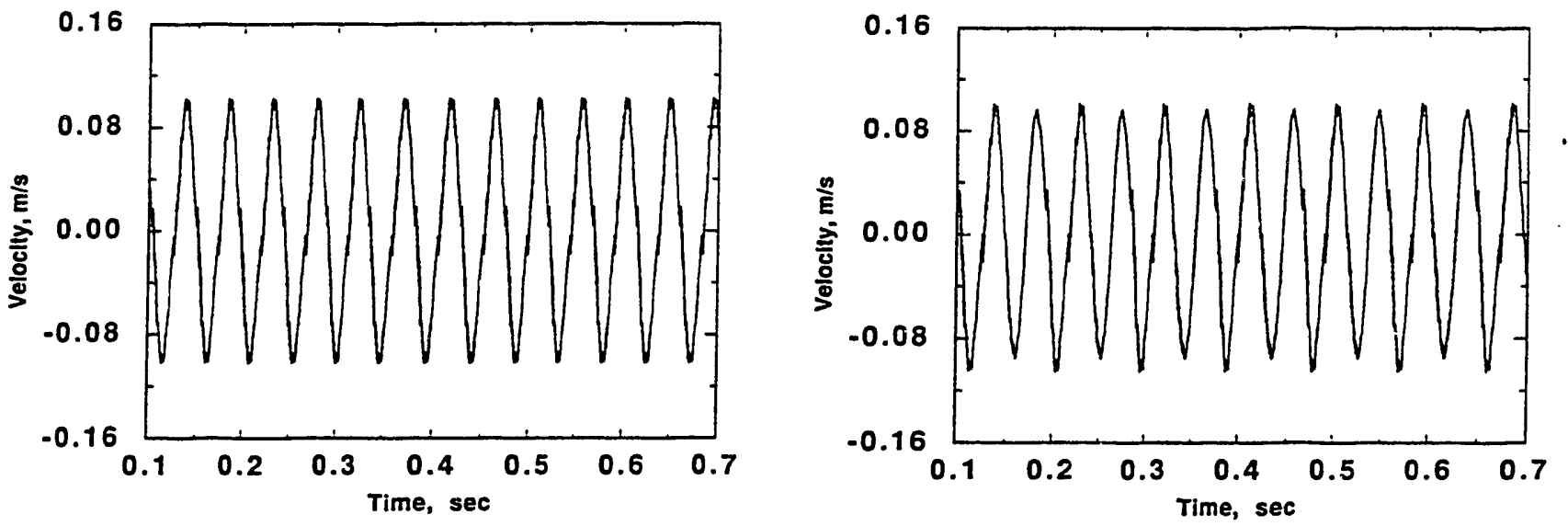

a-2

Velocity

b-2
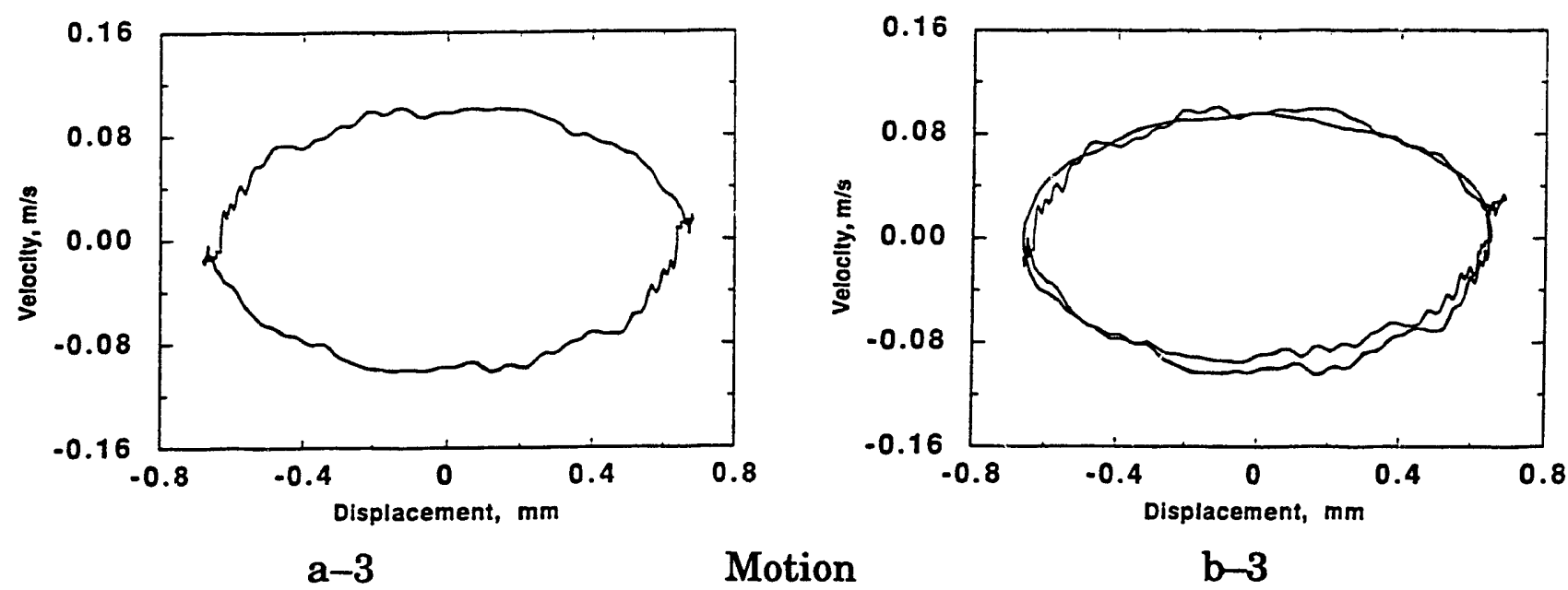

(a) $U_{m}=1.8 \mathrm{~m} / \mathrm{s}$

(b) $U_{\mathrm{m}}=1.7 \mathrm{~m} / \mathrm{s}$

Fig. 13. Time history of tube displacement, velocity, and motion at $\xi=0.4$ with (a) $U_{m}=1.8 \mathrm{~m} / \mathrm{s}$, (b) $U_{m}=1.7 \mathrm{~m} / \mathrm{s}$, (c) $U_{m}=1.6 \mathrm{~m} / \mathrm{s}$, and (d) $U_{m}=1.55 \mathrm{~m} / \mathrm{s}$ 

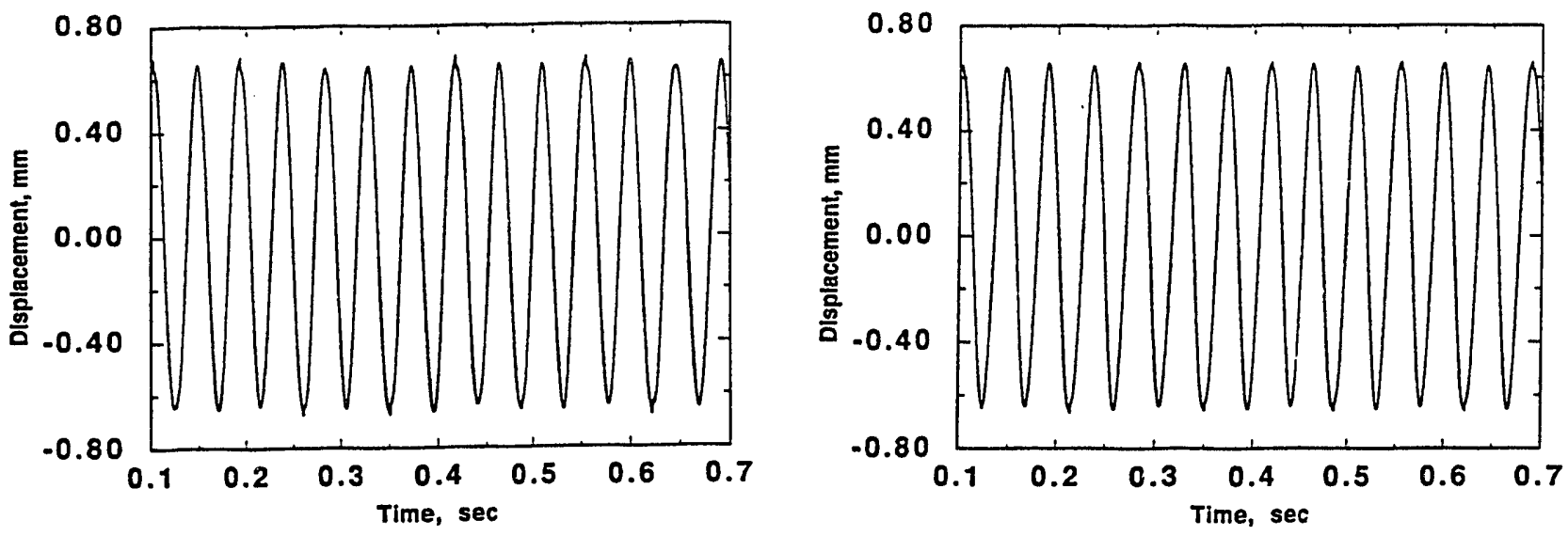

c-1

Displacement

d-1
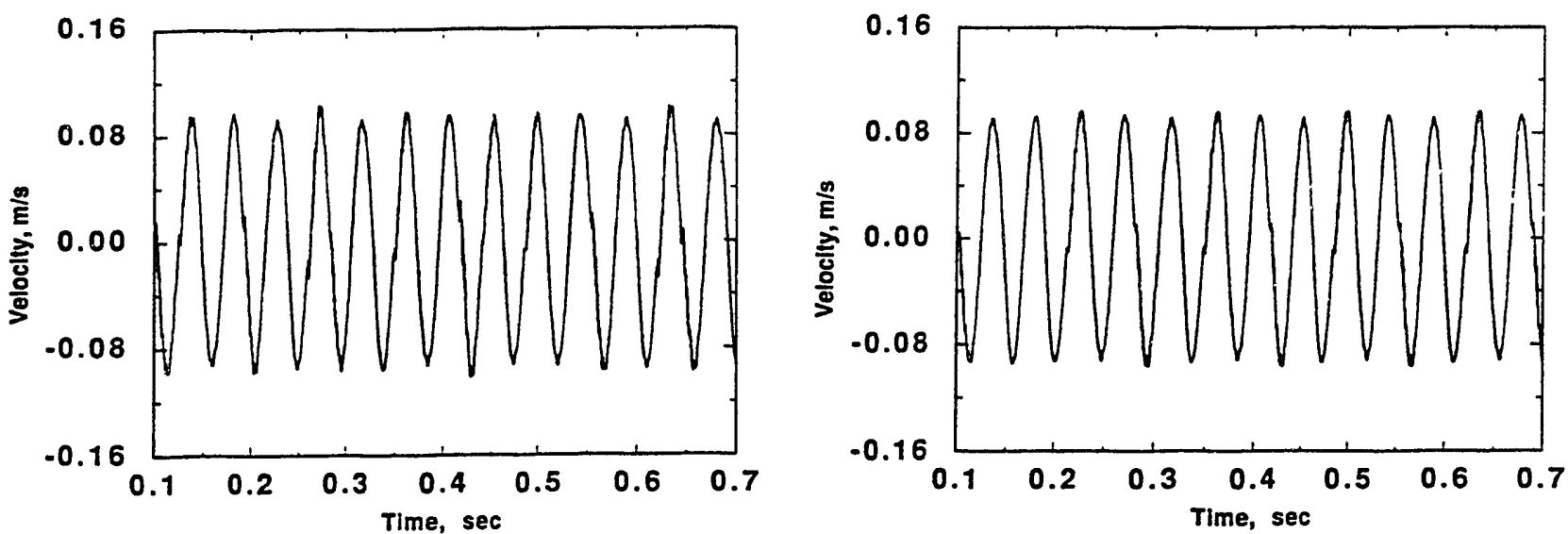

$$
c-2
$$

Velocity

$$
d-2
$$
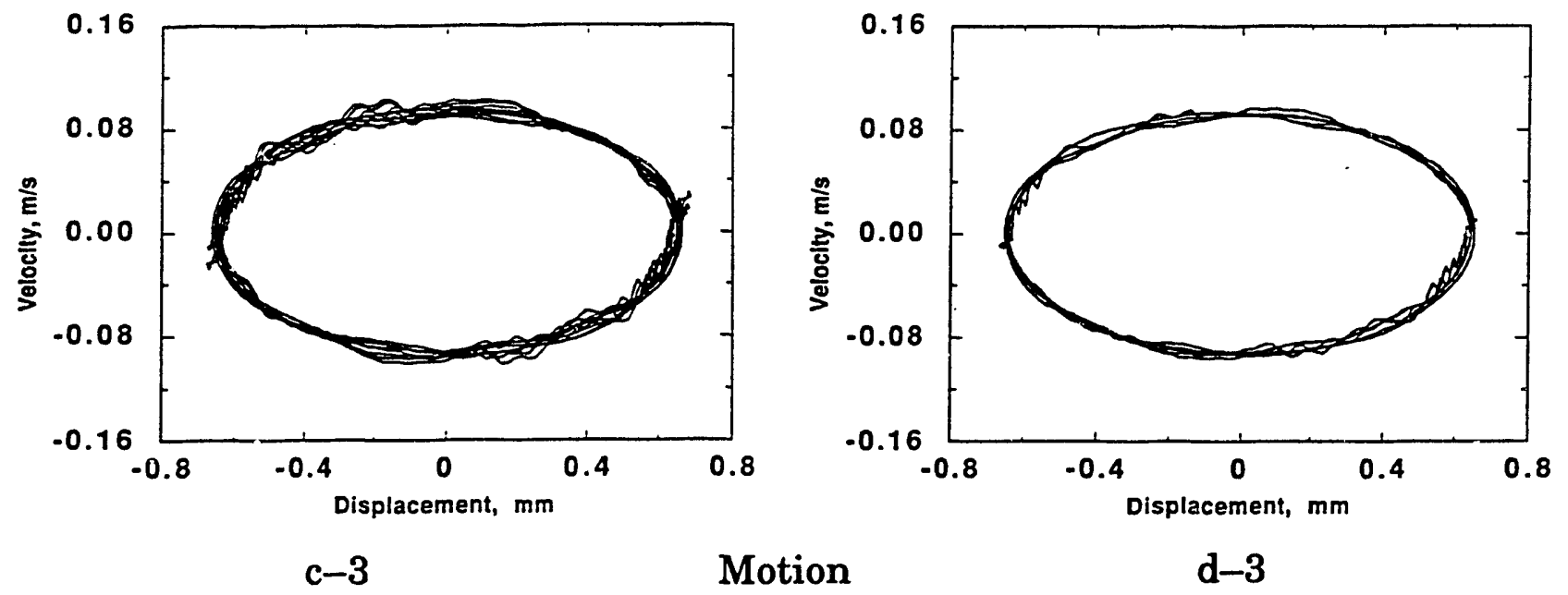

Motion

d-3

(c) $\mathrm{U}_{\mathrm{m}}=1.6 \mathrm{~m} / \mathrm{s}$

(d) $U_{m}=1.55 \mathrm{~m} / \mathrm{s}$

Fig. 13. (Cont'd) 


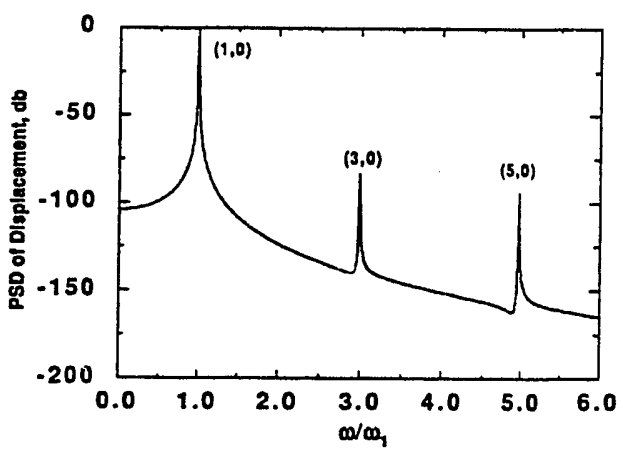

(a)

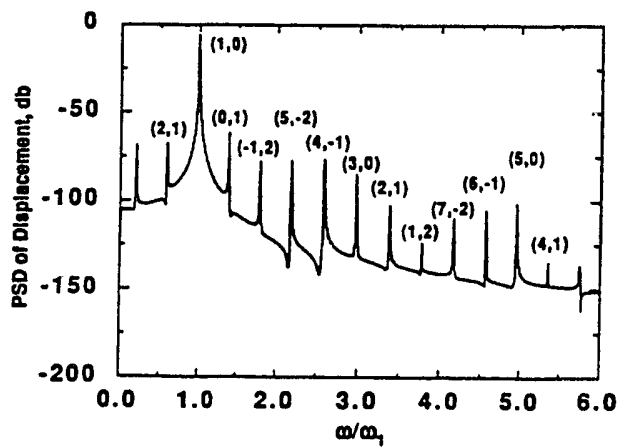

(b)

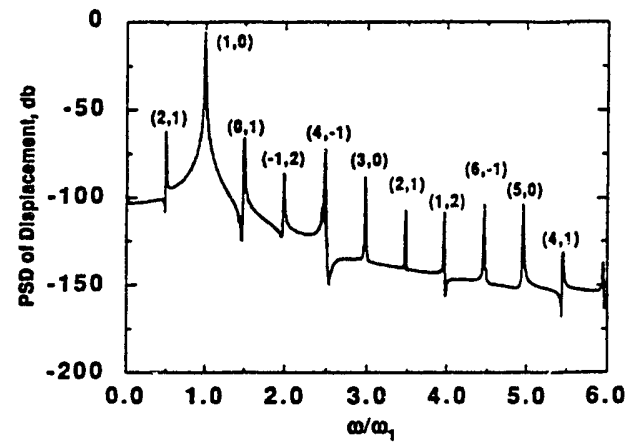

(c)

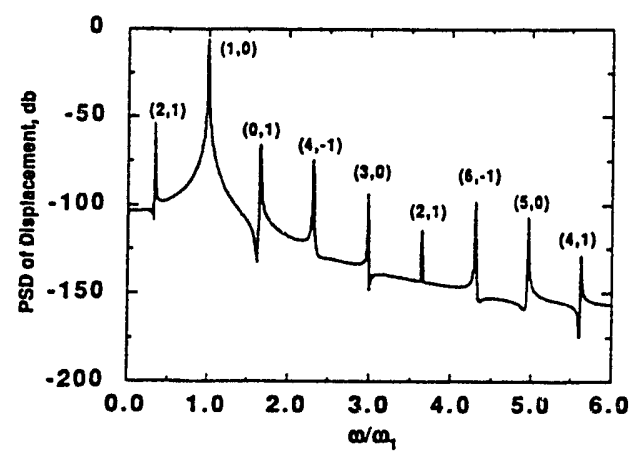

(d)

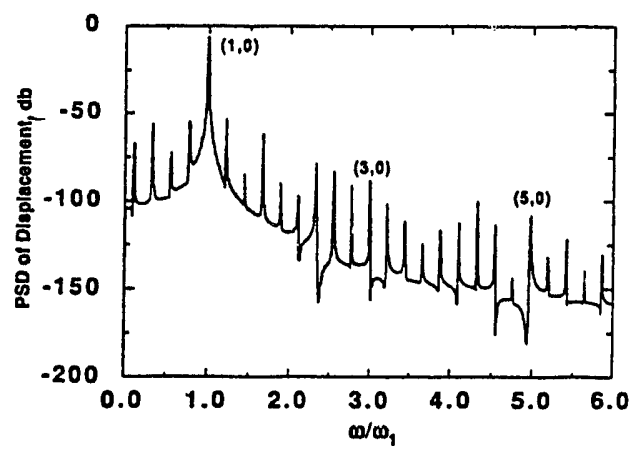

(e)

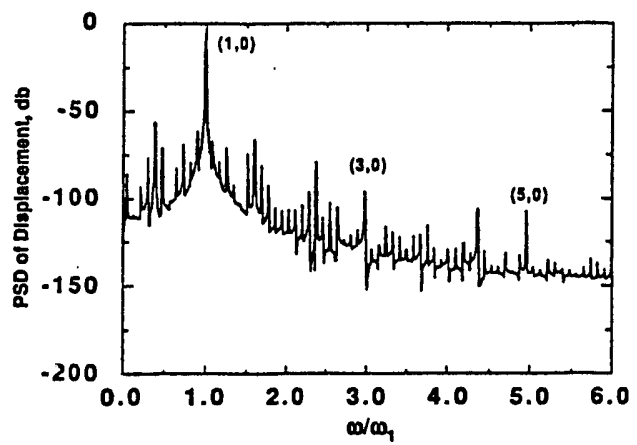

(f)

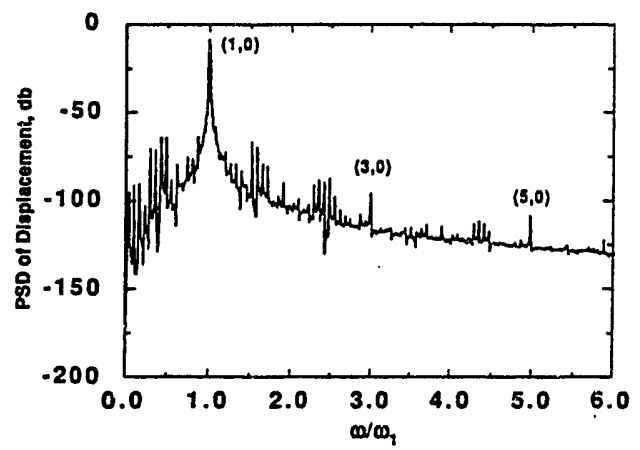

(g)

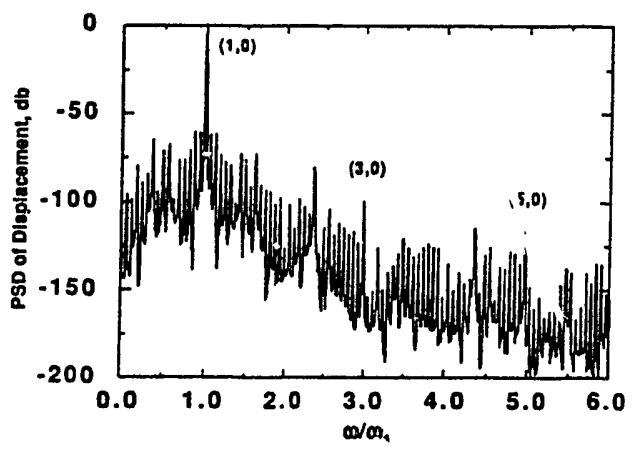

(h)

Fig. 14. Power spectral density of tube displacement with (a) $U_{m}=1.8 \mathrm{~m} / \mathrm{s}$, (b) $U_{m}=1.75 \mathrm{~m} / \mathrm{s}$, (c) $U_{m}=1.7 \mathrm{~m} / \mathrm{s}$, (d) $U_{m}=1.67 \mathrm{~m} / \mathrm{s}$, (e) $U_{m}=1.65 \mathrm{~m} / \mathrm{s}$, (f) $U_{m}=1.62 \mathrm{~m} / \mathrm{s}$, (g) $U_{m}=1.6 \mathrm{~m} / \mathrm{s}$, and (h) $U_{m}=1.57 \mathrm{~m} / \mathrm{s}$ 
PSDs of tube motions within the quasiperiodic region for flow velocities $U_{m}=1.75$, $1.7,1.67,1.65 \mathrm{~m} / \mathrm{s}$, respectively. A few well-pronounced peaks could be found in these PSDs. It is known that the quasiperiodic motion presents two simultaneous periodic oscillations, namely the two incommensurate fundamental frequencies $\omega_{1}$ and $\omega_{2}$. Hence the frequencies appearing in the spectrum of quasiperiodic motion can be a combination of these two incommensurate frequencies, i.e.,

$$
\omega_{\mathrm{mn}}=\mathrm{m} \omega_{1}+\mathrm{n} \omega_{2}
$$

Table 2 shows the indexing of the peaks in Figs. 14b-14d. We noted that the first fundamental frequency remains the same no matter how the flow velocity changes. However, the second frequency changes with flow velocity. Physically, the change of the second frequency is related to the number of impacts during certain cycles. From Fig. 14 and Table 2, it seems to be difficult to say with certainty that the motions are clearly of period 2 or of period 4 as described by Paidoussis and Moon.35 But there is no doubt that this motion is quasiperiodic. These effects, caused by nonlinear instability of the TSP-inactive mode, were also found by Antunes, et al., but those authors did not point this out even though clear quasiperiodic peaks existed in Figs. 5 and 6 of their paper. ${ }^{11}$

Figures 14f-14h, for flow velocities $U_{m}=1.62,1.6$, and 1.57, show the PSD of tube displacements. These PSDs are characteristic of limited-band chaos, although the fundamental frequency and superharmonic frequencies are still discernible.

\subsection{Poincaré Map}

The Poincaré map is a powerful technique for distinguishing chaotic responses from periodic responses or random noise. The map represents a discretization of a continuous flow in the phase space of a dynamic system. Discrete points are selected in response to some trigger; for forced vibration with a periodic input, for instance, the time variable at some identifiable point of the period usually serves as the triggering signal. For an autonomous system, however, one must choose some plane in the phase space, transverse to the flow, and then obtain a Poincaré section. 28

A more general concept of the Poincare map, valid for autonomous systems, has been given by Dowell.38 The strobed points in the Poincaré map give an immediate answer about the periodicity of the response. The Poincare map of a harmonic motion is a single point in the phase plane. A subharmonic motion of order $\mathbf{N}$ has a Poincaré map comprising $\mathbf{N}$ points (its period is $\mathbf{N}$ times the period of excitation), while in the case of chaos, the map has a complex fractal 
Table 2. Indexing of peaks of Fig. 14

(a) Fig. $14 \mathrm{~b}, \mathrm{U}_{\mathrm{m}}=1.75 \mathrm{~m} / \mathrm{s}, \mathrm{f}_{1}=22.28 \mathrm{~Hz}$, $f_{2}=31.13 \mathrm{~Hz}$

\begin{tabular}{lcc}
\hline$(\mathrm{m}, \mathrm{n})$ & $\mathrm{f}_{(\mathrm{m}, \mathrm{n})}(\mathrm{Hz})$ & $\mathrm{mf}_{\mathbf{1}}+\mathrm{nf}_{\mathbf{2}}(\mathrm{Hz})$ \\
\hline$(3,-2)$ & 4.578 & 4.580 \\
$(2,-1)$ & 13.4 & 13.43 \\
$(1,0)$ & 22.28 & 22.28 \\
$(0,1)$ & 31.13 & 31.13 \\
$(-1,2)$ & 39.67 & 39.98 \\
$(5,-2)$ & 48.52 & 49.14 \\
$(4,-1)$ & 57.37 & 57.99 \\
$(3,0)$ & 66.22 & 66.22 \\
$(2,1)$ & 74.77 & 75.69 \\
$(1,2)$ & 83.62 & 84.54 \\
$(7,-2)$ & 92.47 & 93.70 \\
$(6,-1)$ & 101.3 & 102.6 \\
$(5,0)$ & 109.9 & 109.9 \\
$(4,1)$ & 118.7 & 120.3 \\
\hline
\end{tabular}

(b) Fig. 14c, $U_{m}=1.7 \mathrm{~m} / \mathrm{s}, f_{1}=22.28 \mathrm{~Hz}$, $\mathrm{f}_{2}=33.26 \mathrm{~Hz}$

\begin{tabular}{lcc}
\hline$(\mathrm{m}, \mathrm{n})$ & $\mathrm{f}_{(\mathrm{m}, \mathrm{n})}(\mathrm{Hz})$ & $\mathrm{mf}_{\mathbf{1}}+\mathrm{nf}_{2}(\mathbf{H z})$ \\
\hline$(2,-1)$ & 11.29 & 11.30 \\
$(1,0)$ & 22.28 & 22.28 \\
$(0,1)$ & 33.26 & 33.26 \\
$(-1,2)$ & 44.25 & 44.24 \\
$(4,-1)$ & 55.24 & 55.86 \\
$(3,0)$ & 66.22 & 66.22 \\
$(2,1)$ & 77.21 & 77.82 \\
$(1,2)$ & 88.20 & 88.80 \\
$(6,-1)$ & 98.88 & 100.4 \\
$(5,0)$ & 109.9 & 109.9 \\
$(4,1)$ & 120.8 & 122.4 \\
\hline
\end{tabular}

(c) Fig. 14d, $\mathrm{U}_{\mathrm{m}}=1.67 \mathrm{~m} / \mathrm{s}, \mathrm{f}_{1}=22.28 \mathrm{~Hz}$, $\mathrm{f}_{2}=36.93 \mathrm{~Hz}$

\begin{tabular}{lcc}
\hline$(\mathrm{m}, \mathrm{n})$ & $\mathrm{f}_{(\mathrm{m}, \mathrm{n})}(\mathrm{Hz})$ & $\mathrm{mf}_{1}+\mathrm{nf}_{2}(\mathrm{~Hz})$ \\
\hline$(2,-1)$ & 7.629 & 7.630 \\
$(1,0)$ & 22.28 & 22.28 \\
$(0,1)$ & 36.93 & 36.93 \\
$(4,-1)$ & 51.57 & 52.19 \\
$(3,0)$ & 66.22 & 66.22 \\
$(2,1)$ & 81.67 & 81.49 \\
$(6,-1)$ & 95.21 & 96.75 \\
$(5,0)$ & 109.9 & 109.9 \\
$(4,1)$ & 124.5 & 126.1 \\
\hline
\end{tabular}


structure. 28 In our case, it is an autonomous system. The problem in generating a Poincaré map is that there are many possibilities for choosing a plane. After numerous trial runs, we chose the triggering signal, say when $\dot{v}(1, t)=0$ and $u(1, t)>0$, at which point the values of $u(0.2, t)$ and $\dot{u}(0.2, t)$ would be saved.

Figures $15 \mathrm{a}-15 \mathrm{~g}$ show such Poincaré maps, corresponding to flow velocities $\mathrm{U}_{\mathrm{m}}=1.8,1.75,1.7,1.67,1.65,1.6$, and $1.55 \mathrm{~m} / \mathrm{s}$, respectively. In Fig. 15a, the flow velocity $U_{m}=1.8 \mathrm{~m} / \mathrm{s}$, which presents a periodic motion; there, only one basin of attraction exists. In Fig. 15c, however, $U_{m}=1.7 \mathrm{~m} / \mathrm{s}$, which presents a typical period-2 motion (see Fig. 11b-3); hence two basins of attraction exist in the Poincaré map. Figures $15 \mathrm{~b}, 15 \mathrm{~d}$, and 15e, with flow velocities $U_{m}=1.75,1.67$, and $1.65 \mathrm{~m} / \mathrm{s}$, present quasiperiodic motion, but we could not say exactly what their periods are (see Figs. 14b, 14d, 14e, and Table 2); therefore, there are two morescattered basins in these Poincaré maps, which is still characteristic of quasiperiodic motion and agrees well with the PSD results in Fig. 14. On the other hand, in Figs. $15 \mathrm{f}$ and $15 \mathrm{~g}$, with flow velocities $U_{m}=1.6$ and $1.55 \mathrm{~m} / \mathrm{s}$, the motions are limited-band chaotic with points scattered over wide ranges. In that case, although the Poincare maps do not display artistic merits because the motion may be a limited chaotic or because the maps require much longer computation time, they nevertheless do seem to have some structure.

It is satisfying for us to observe that the results from the Poincare maps are in good agreement with those obtained from the bifurcation diagram, phase portraits, and power spectral density.

\section{Conclusions}

A mathematical methodology based on the unsteady flow theory and linear modal analysis is presented in this report for fluidelastic instability of loosely supported tubes subjected to nonuniform crossflow. An extensive study on the characteristics of fluidelastic instability of tubes in the unstable region associated with the TSP-inactive mode, has been conducted, with particular attention given to the possible existence of chaotic oscillation.

Based on a bilinear model described in Section 3, the fluidelastic instability of loosely supported tubes can be expressed by an autonomous mechanical system, and the closed-form solution is obtained to investigate the fluidelastic instability and possible chaotic motion. The importance of this, to our best knowledge, is that this is the first application of the closed-form solution of an autonomous system in exploring the chaotic motion of loosely supported tubes that is induced by fluidelastic instability. 


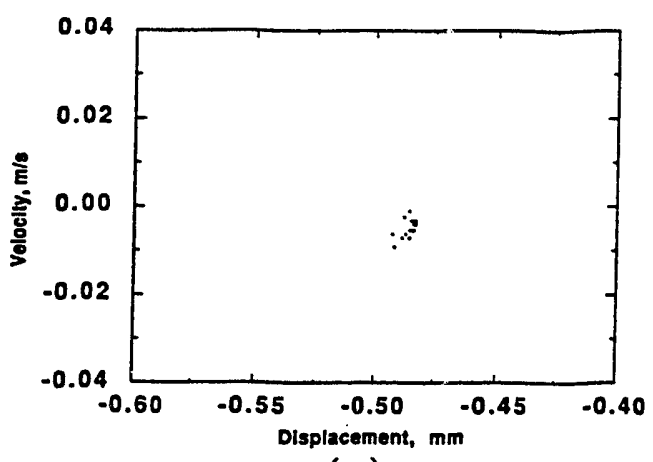

(a)

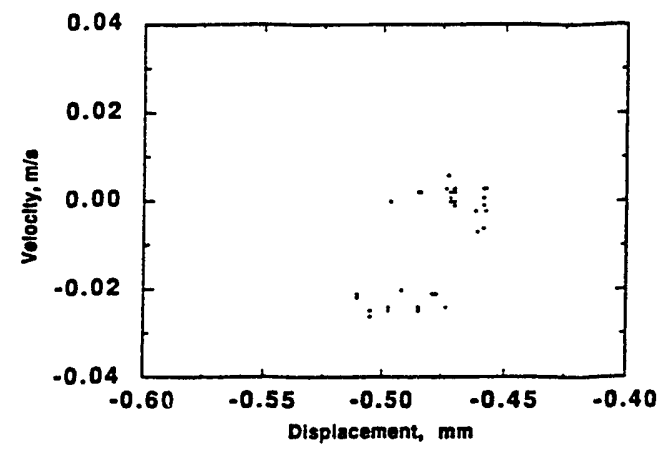

(b)

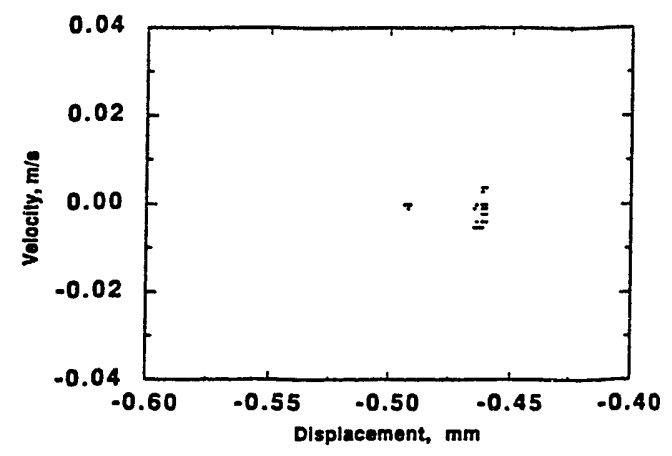

(c)

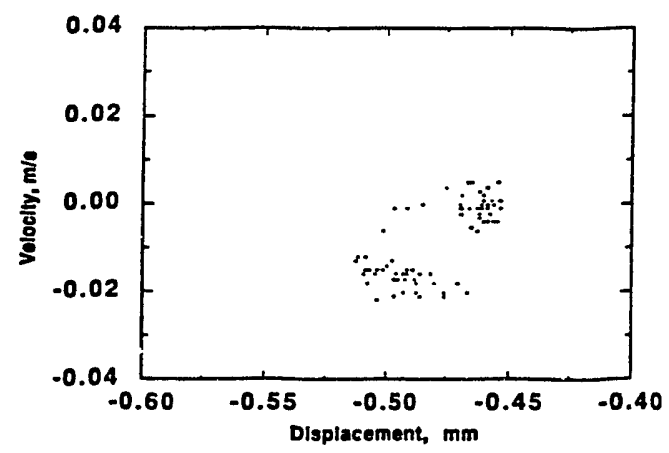

(d)

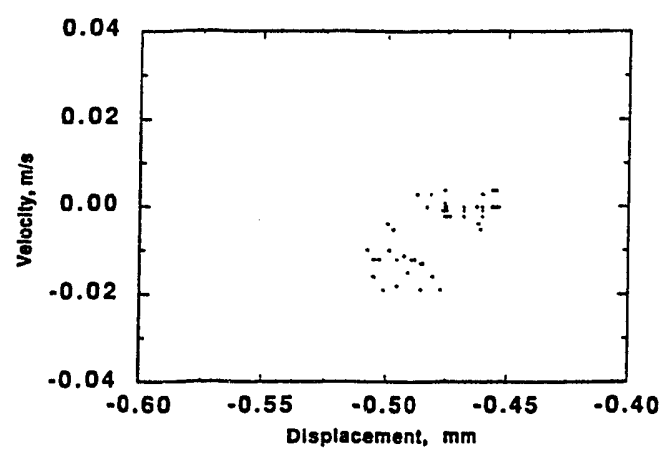

(e)

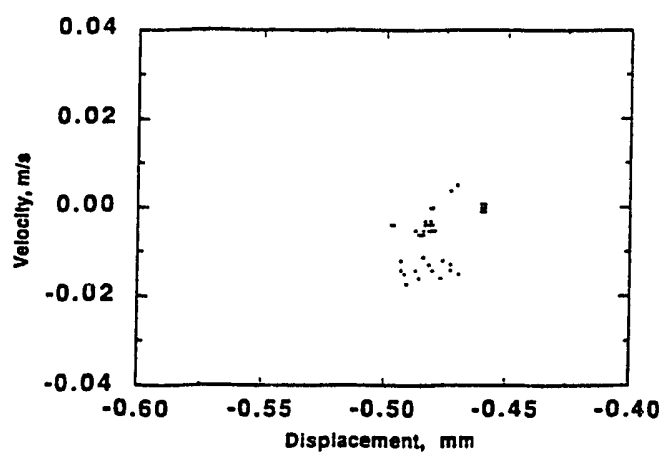

(f)

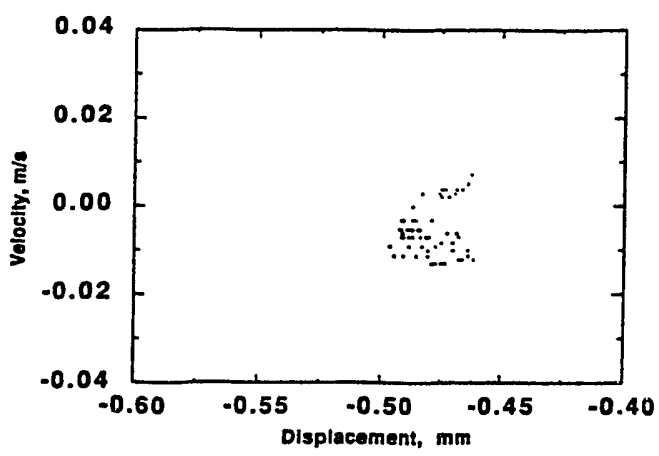

(g)

Fig. 15. Poincaré map of tube motion at $\xi=0.2$ with (a) $U_{m}=1.8 \mathrm{~m} / \mathrm{s}$, (b) $U_{m}=$ $1.75 \mathrm{~m} / \mathrm{s}$, (c) $U_{m}=1.7 \mathrm{~m} / \mathrm{s}$, (d) $U_{m}=1.67 \mathrm{~m} / \mathrm{s}$, (e) $U_{m}=1.65 \mathrm{~m} / \mathrm{s}$, (f) $U_{m}=$ $1.6 \mathrm{~m} / \mathrm{s}$, and $(\mathrm{g}) U_{m}=1.55 \mathrm{~m} / \mathrm{s}$ 
For simplification when we began the investigation of chaotic motion, we chose only a single tube with fixed symmetric clearance at the end of the TSP; other parameters, such as contact stiffness and mass-damping, were given as specific values according to previous experiments and other available literature. Also, we did not consider the instability region associated with the TSP-active mode, even though there is a high probability of chaotic motion, because once a TSP-active mode becomes unstable, other nonlinear effects become important and those effects are not included in this model.

As suggested in most investigations on chaotic motions, $\mathbf{3 5}$ it is important to use more than one measurement in deciding on the existence of chaos. Thus we carried out the calculations of RMS displacement of tube motion, bifurcation diagram, phase flow portraits, power spectral density, and Poincaré maps to confirm the different instability regions.

As shown in RMS displacement of tube motion, when flow velocity is lower than the threshold value of critical flow velocity, tube motion is in a stable region and its vibration will die out as time increases.

When a tube becomes unstabie in the TSP-inactive mode and the flow velocity exceeds a certain value, the tube will impact the TSP regularly (twice per cycle). Because of the support constraints, large tube oscillations do not occur and with flow velocity increased further, tube displacement remains almost constant. This region is periodic, with superharmonics (see PSD in Fig. 14a). Its phase portrait is a repeated circle (Fig. 11c-1) and the Poincaré map shows one basin of attraction.

However, when flow velocity just exceeds critical flow velocity, the tube will impact the TSP irregularly. Construction of a bifurcation diagram has shown that chautic motions do indeed arise (Figs. 9 and 10). In this region, phase portraits show a band circle, which indicates a limited-band chaotic motion (Fig. 11). PSD results have confirmed these findings, by showing that the spectra seem to be a continuous broad response (see Figs. 14f $-14 \mathrm{~h}$ ). The Poincare map gives a scattered structure (Figs. $15 \mathrm{f}$ and $15 \mathrm{~g}$ ) in the chaotic region.

Between the regions of periodic and chaotic motions is a quasiperiodic region that shows the characteristics of doubling period: ity. It is clearly observed in power spectral density that, except for the fundamental frequency, there are other distinct peaks that are definitely a combination of the two fundamental frequencies. The second fundamental frequency will vary with flow velocity (see Figs. 14b-14e and Table 2). 
Indeed, chaotic motion is demonstrated as possible for such an autonomous system when simulated by a bilinear model. Furthermore, this chaotic motion is through a route from periodic and quasiperiodic to chaotic as flow velocity decreases in the instability region of the TSP-inactive mode.

Obviously, further research on the fluidelastic instability of loosely supported tubes is still needed. Chaotic motion will be measured with new tools, including the probability density function, the autocorrelation function, and Lyapunov exponents. Also, additional extensive parametric analyses will be conducted to explore chaotic behavior in more detail. Various diametric clearances, including asymmetric, will be applied to the current system. Various contact stiffnesses and mass-damping parameters will also be tested. Furthermore, a row of multitubes and excitation forces will be considered with modified mathematical models to investigate instability and chaos for practical applications.

\section{Acknowledgments}

This work was sponsored by the U.S. Department of Energy, Office of Basic Energy Sciences, Division of Engineering and Geosciences.

\section{References}

1. Chen, S. S., Jendrzejczyk, J. A., and Wambsganss, M. W., Dynamics of Tubes in Fluid with Tube-Baffle Interaction, ASME Symp. on Flow-Induced Vibration, New Orleans, Vol. 2, pp. 285-304 (1984).

2. Haslinger, K. H., Martin, M. L., and Steininger, D. A., Pressurized Water Reactor Steam Generator Tube Wear Prediction Utilizing Experimental Techniques, International Conf. on Flow Induced Vibrations, Bowness-onWindermere, England, Paper K2, pp. 437-448 (1987).

3. Antunes, J., Axisa, F., Beaufils, B., and Guilbaud, D., Coulomb Friction Modelling in Numerical Simulations of Vibration and Wear Work Rate of Multispan Tube Bundles, International Symp. on Flow-Induced Vibration and Noise, Chicago, Vol. 5, pp. 157-176 (1988).

4. Godon, J. L., and Lebret, J., Influence of the Tube-Support Plate Clearance on Flow-Induced Vibration in Large Condensers, International Symp. on Flow-Induced Vibration and Noise, Chicago, Vol. 5, pp. 177-186 (1988). 
5. Yeh, Y. S., and Chen, S. S., Flow-Induced Vibration of Component Cooling Water Heat Exchangers, ASME Pressure Vessels and Piping Conf., Nashville, TN, PVP Vol. 189, pp. 153-163 (1990).

6. Yu, X., An Analysis of Tube Failure in a U-shape Tube Bundle, ASME Pressure Vessels and Piping Conf., Chicago, PVP Vol. 104, pp. 187-192 (1986).

i. Fisher, N. J., and Ingham, B., Measurement of Tube-to-Support Dynamic Force in Fretting-Wear Rigs, International Symp. on Flow-Induced Vibration and Noise, Chicago, Vol. 5, pp. 137-156 (1988).

8. Haslinger, K. H., Martin, M. L., and Steininger, D. A., Experimental Characterization of Fluid and Squeeze Film Effects in Heat Exchanger Tube Supports, Flow-Induced Vibration - 1989, ASME Pressure Vessels and Piping Conf., PVP Vol. 154, pp. 31-41 (1989).

9. Ko, P. L., and Magel, E., Impact and Sliding Wear in Steam Generators and Heat Exchangers: New Experimental Test Rig and Wear Model, FlowInduced Vibration - 1989, ASME Pressure Vessels and Piping Conf., PVP Vol. 154, pp. 63-69 (1989).

10. Nakamura, T., and Fujita, K., A Study on Impact Vibration of Loosely Held Tube by Cross Flow, International Conf. on Flow Induced Vibrations, Bowness-on-Windermere, England, Paper K1, pp. 427-436 (1987).

11. Antunes, J., Axisa, F., and Vento, M. A., Experiments on Vibro-Impact Dynamics Under Fluidelastic Instability, ASME Pressure Vessels and Piping Conf., Nashville, TN, PVP Vol. 189, pp. 127-138 (1990).

12. Rao, M. S. M., et al., Computer Modelling of Vibration and Wear of Multispan Tubes with Clearances at Tube Supports, International Conf. on Flow Induced Vibrations, Bowness-on-Windermere, England, Paper K3, pp. 449-466 (1987).

13. Fisher, N. J., Olesen, M. J., Rogers, R. J., and Ko, P. L., Simulation of Tubeto-Support Dynamic Interaction in Heat Exchange Equipment, International Symp. on Flow-Induced Vibration and Noise, Chicago, Vol. 5, pp. 121-136 (1988).

14. Fricker, A. J., Numerical Analysis of the Fluidelastic Vibration of a Steam Generator Tube with Loose Supports, International Symp. on Flow-Induced Vibration and Noise, Chicago, Vol. 5, pp. 105-120 (1988). 
15. Rao, M. S. M., Steininger, D. A., and Eisinger, F. L., Numerical Simulation of Fluidelastic Vibration and Wear of Multispan Tubes with Clearances at Supports, International Symp. on Flow-Induced Vibration and Noise, Chicago, Vol. 5, pp. 235-250 (1988).

16. Goyder, N. G. D., and Teh, C. E., A Study of the Impact Dynamics of Loosely Supported Heat Exchanger Tubes, International Symp. on Flow-Induced Vibration and Noise, Chicago, Vol. 5, pp. 87-104 (1988).

17. Eisinger, F. L., Rao, M. S. M., and Steininger, D. A., Numerical Simulation of Fluid Instability of Multispan Tubes Partially Exposed to Crossflow, Trans. 10th SMiRT, Vol. T, pp. 45-56 (1989).

18. Andjelic, M., Austermann, R., and Popp, K., Multiple Stability Boundaries of Tubes in a Normal Triangular Cylinder Array, ASME Pressure Vessels and Piping Conf., Nashville, TN, PVP Vol. 189, pp. 87-98 (1990).

19. Chen, S. S., and Jendrzejczyk, J. A., Characteristics of Fluidelastic Instability of Tube Row In Crossflow, International Conf. on Flow Induced Vibrations, Bowness-on-Windermere, England, Paper B3, pp. 77-\$44 (1987).

20. Axisa, F., Antunes, J., and Villard, B., Overview of Numerical Methods for Predicting Flow-Induced Vibration, Trans. ASME Pressure Vessels and Piping, Vol. 110, pp. 6-14 (1988).

21. Andjelic, M., and Popp, K., Stability Effects in a N'ormal Triangular Cylinder Array, J. Fluid Structure, Vol. 3, pp. 165-185 (1989).

22. Chen, S. S., Some Issues Concerning Fluidelastic Instability of a Group of Circular Cylinders in Cross-Flow, Trans. ASME, J. Press. Vessel Technol., Vol. 111, pp. 507-518 (1989).

23. Chen, S. S., and Chandra, S., Fluidelastic Instabilities in Tube Bundles Exposed to Nonuniform Crossflow, ASME Pressure Vessels and Piping Conf., Nashville, TN, PVP Vol. 189, pp. 65-77 (1990).

24. Tanaka, M., Study on Fluidelastic Vibrations of Tube Bundle, Jpn. Soc. Mech. Eng., Trans., Section B, Vol. 46(408), pp. 1398-1407 (1980).

25. Chen, S. S., and Jendrzejczyk, J. A., Stability of Tube Arrays in Crossflow, Nucl. Eng. Des., Vol. 75(3), pp. 351-374 (1983). 
26. Cai. Y., Chen, S. S., and Chandra, S., A Theory for Fluidelastic Instability of Tube-Support-Plate Inactive Modes, Argonne National Laboratory, Report ANL-90/38 (Sept. 1990).

27. Guckenheimer, J., and Holmes, P. J., Nonlinear Oscillations, Dynamical Systems and Bifurcations of Vector Fields, New York: Springer-Verlag (1983).

28. Moon, F. C., Chaotic Vibrations, New York: John Wiley (1987).

29. Thompson, J. M. T., and Stewart, H. B., Nonlinear Dynamics and Chaos, New York: John Wiley (1986).

30. Paidoussis, M. P., Flow-Induced Instabilities of Cylindrical Structures, Appl. Mech. Rev., Vol. 40, pp. 163-165 (1987).

31. Moon, F. C., and Shaw, S. W., Chaotic Vibrations of a Beam with Non-Linear Boundary Conditions, Int. J. Non-Linear Mechanics, Vol. 18, pp. 465-477 (1983).

32. Shaw, S. W., and Folmes, P. J., A Periodically Forced Piecewise Linear Osciliaior, J. Sound Vib., Vol. 90, pp. 129-155 (1983).

33. Shaw, S. W., The Dynamics of a Harmonically Excited System Having Rigid Amplitude Constraints; Parts I and II, ASME J. Appl. Mech., Vol. 52, pp. 453-458 and pp. 459-469 (1985).

34. Shaw, S. W., Forced Vibrations of a Beam with One-Sided Amplitude Constraint: Theory and Experimeni, J. Sound Vib., Vol. 99, pp. 199-212 (1985).

35. Paidoussis, M. P., and Moon, F. C., Nonlinear and Chaotic Fluidrlastic Vibrations of a Flexible Pipe Conveying Fluid, J. Fluids and Structures, Vol. 2, pp. 567-591 (1988).

36. Paidoussis, M. P., and Moon, F. C., Chaotic Oscillations of the Autonomous System of a Constrained Pipe Conveying Fluid, J. Sound Vib., Vol. 135(1), pp. 1-19 (1989).

37. Langre, E. de, et al., Chaotic and Periodic Motion of a Non-Linear Oscillator in Relation with Flow-Induced Vibrations of Loosely Supported Tubes, ASME Pressure Vessels and Piping Conf., Nashville, TN, PVP Vol. 189, pp. 119-125 (1990). 
38. Dowell, E. H., Observation and Evolution of Chaos for an Autonomous System, ASME J. Appl. Mech., Vol. 51, pp. 333-344 (1984). 


\section{Appendix: \\ Modal Analysis of a Bilinear Model}

For Model 1, if we assume that during the time interval $0 \leq t \leq t_{s}$, the tube displacements at C3 are within the stop limits $-e_{2}<u(\ell, t)<e_{1}$, the boundary conditions at C1 and C3 (Fig. 3) are

$$
\begin{aligned}
& \left.u\left(\xi_{1}, t\right)\right|_{\xi_{1}=0}=0, \\
& \left.\frac{\partial^{2} u}{\partial \xi_{1}^{2}}\left(\xi_{1}, t\right)\right|_{\xi_{1}=0}=0, \\
& \left.\frac{\partial^{2} u}{\partial \xi_{2}^{2}}\left(\xi_{2}, t\right)\right|_{\xi_{2}=0}=0, \\
& \left.\frac{\partial^{3} u}{\partial \xi_{2}^{3}}\left(\xi_{2}, t\right)\right|_{\xi_{2}=0}=0,
\end{aligned}
$$

and the continuous conditions at the intermediate point $\mathrm{C} 2$ are

$$
\begin{aligned}
& \left.u\left(\xi_{1}, t\right)\right|_{\xi_{1}=\mu}=\left.u\left(\xi_{2}, t\right)\right|_{\xi_{2}=v}=0, \\
& \frac{d \varphi_{1 n}^{(1)}(\mu)}{d \xi_{1}}=-\frac{d \varphi_{1 n}^{(2)}(v)}{d \xi_{2}}, \\
& \frac{d^{2} \varphi_{1 n}^{(1)}(\mu)}{d \xi_{1}^{2}}=-\frac{d^{2} \varphi_{1 n}^{(2)}(v)}{d \xi_{2}^{2}}
\end{aligned}
$$

where $\xi_{1}, \xi_{2}, \mu$, and $v$ are dimensionless distances

$$
\begin{array}{ll}
\xi_{1}=\mathrm{z}_{1} / \ell, & \xi_{2}=\mathrm{z}_{2} / \ell, \\
\mu=\ell_{1} / \ell, & v=\ell_{2} / \ell .
\end{array}
$$

The functions $\varphi_{1 \mathrm{n}}^{(1)}$ and $\varphi_{\mathrm{ln}}^{(2)}$ are normal modes of Model 1

$$
\varphi_{1 \mathrm{n}}^{(1)}\left(\xi_{1}\right)=\sin \mathrm{k}_{\mathrm{n}_{1}} \xi_{1}-\frac{\sin \mathrm{k}_{\mathrm{n}_{1}} \mu}{\operatorname{sh~} \mathrm{k}_{\mathrm{n}_{1}} \mu} \operatorname{sh} \mathrm{k}_{\mathrm{n}_{1}} \xi_{1}, \quad 0<\xi_{1}<\mu, \quad \mathrm{n}_{1}=1,2,3, \ldots,
$$




$$
\begin{aligned}
& \varphi_{1 \mathrm{n}}^{(2)}\left(\xi_{2}\right)=\left(\operatorname{cosk}_{\mathrm{n}_{1}} \mu-\sin \mathrm{k}_{\mathrm{n}_{1}} \mu \operatorname{cth} \mathrm{k}_{\mathrm{n}_{1}} \mu\right) \\
& \frac{\left[\left(\sin \mathrm{k}_{\mathrm{n}_{1}} v+\operatorname{sh} \mathrm{k}_{\mathrm{n}_{1}} v\right)\left(\cos \mathrm{k}_{\mathrm{n}_{1}} \xi_{2}+\operatorname{chk}_{\mathrm{n}_{1}} \xi_{2}\right)-\left(\cos \mathrm{k}_{\mathrm{n}_{1}} v+\operatorname{ch}_{\mathrm{n}_{1}} v\right)\left(\sin \mathrm{k}_{\mathrm{n}_{1}} \xi_{2}+\operatorname{sh} \mathrm{k}_{\mathrm{n}_{1}} \xi_{2}\right)\right]}{2\left(1+\cos \mathrm{k}_{\mathrm{n}_{1}} v \operatorname{ch} \mathrm{k}_{\mathrm{n}_{1}} v\right)},
\end{aligned}
$$

$$
0<\xi_{2}<v, \quad n_{1}=1,2,3, \ldots
$$

where the eigenvalues $k_{n_{1}}$ are the solutions of the characteristic equation

$$
\frac{\sin k_{n_{1}} \mu}{\cos k_{n_{1}} \mu-\sin k_{n_{1}} \mu \operatorname{cth} k_{n_{1}} \mu}-\frac{\operatorname{cosk}_{n_{1}} v \operatorname{sh} k_{n_{1}} v-\sin k_{n_{1}} v \operatorname{ch} k_{n_{1}} v}{2\left(1+\cos k_{n_{1}} v \operatorname{chk} k_{n_{1}} v\right)}=0 .
$$

Let

$$
\begin{aligned}
& \varphi_{\ln }(\xi)= \begin{cases}\mathrm{C}_{\ln } \varphi_{\ln }^{(1)}(\xi) & 0<\xi<\mu \\
\mathrm{C}_{\ln } \varphi_{\ln }^{(2)}(1-\xi) & \mu<\xi<1,\end{cases} \\
& \xi=z / \ell,
\end{aligned}
$$

where

$$
C_{1 n}=\frac{1}{\sqrt{\int_{0}^{\mu}\left[\varphi_{1 n}^{(1)}\left(\xi_{1}\right)\right]^{2} d \xi_{1}+\int_{0}^{\nu}\left[\varphi_{1 n}^{(2)}\left(\xi_{2}\right)\right]^{2} d \xi_{2}}}
$$

Assume that the initial conditions of Model 1 are

$$
\begin{aligned}
& \left.u(\xi, t)\right|_{t=0}=u_{1}(\xi), \\
& \left.\frac{\partial u}{\partial t}(\xi, t)\right|_{t=0}=\left.\dot{u}(\xi, t)\right|_{t=0}=\dot{u}_{1}(\xi) .
\end{aligned}
$$

Then the solutions of tube vibration (here considered only in the $\mathrm{x}$ direction) by the normal-mode method can be described as 


$$
\begin{aligned}
& u(\xi, t)=\sum_{n=1}^{\infty} a_{1 n}(t) \varphi_{\ln }(\xi) \\
& 0<\mathrm{t}<\mathrm{t}_{\text {s }} \text {, } \\
& \dot{\mathrm{u}}(\xi, t)=\sum_{n=1}^{\infty} \dot{\mathrm{a}}_{1 \mathrm{n}}(\mathrm{t}) \varphi_{1 \mathrm{n}}(\xi)
\end{aligned}
$$

where $a_{1 n}$ and $\dot{a}_{1 n}(t)$ are the normal coordinates, which are the solutions of following equations:

$$
\begin{aligned}
& \left(1+\gamma_{j} \alpha_{j j}\right) \ddot{a}_{1 n}+\left(2 \xi_{j n_{1}} \omega_{j n_{1}}-\gamma_{j} \frac{U_{r}^{2}}{\pi^{3}} \omega \alpha_{j j}^{d}\right) \dot{a}_{1 n}+\left(\omega_{j n_{1}}^{2}-\gamma_{j} \frac{U_{r}^{2}}{\pi^{3}} \alpha_{j j}^{e}\right) a_{1 n}=0, \\
& a_{1 n}(0)=\int_{0}^{1} u_{1}(\xi) \varphi_{1 n}(\xi) d \xi \\
& \dot{a}_{1 n}(0)=\int_{0}^{1} \dot{u}_{1}(\xi) \varphi_{1 n}(\xi) d \xi .
\end{aligned}
$$

When $t=t_{s}$, the right end of the tube strikes the stop and it becomes Model 2, i.e.,

$$
\left.u(\xi, t)\right|_{\xi=1}=e_{1} \text {, or }\left.u(\xi, t)\right|_{\xi=1}=-e_{2}, \quad t_{s}<t<t_{d},
$$

where $t_{d}$ is the time when the tube leaves the stop at C3.

The displacement and velocity of the tube at $t_{s}$ are taken as the initial conditions of Model 2, hence,

$$
\begin{aligned}
& \left.u(\xi, t)\right|_{t=t_{s}}=\sum_{n=1}^{\infty} a_{1 n}\left(t_{s}\right) \varphi_{1 n}(\xi)=u_{2}(\xi), \\
& \left.\dot{u}(\xi, t)\right|_{t=t_{s}}=\sum_{n=1}^{\infty} \dot{a}_{1 n}\left(t_{s}\right) \varphi_{1 n}(\xi)=\dot{u}_{2}(\xi) .
\end{aligned}
$$

The boundary conditions of Model 2 for $t_{s}<t<t_{d}$ are

$$
\left.u\left(\xi_{1}, t\right)\right|_{\xi_{1}=0}=0
$$




$$
\begin{aligned}
& \left.\frac{\partial^{2} \mathrm{u}}{\partial \xi_{1}^{2}}\left(\xi_{1}, \mathrm{t}\right)\right|_{\xi_{1}=0}=0, \\
& \left.\frac{\partial^{2} \mathrm{u}}{\partial \xi_{2}}\left(\xi_{2}, \mathrm{t}\right)\right|_{\xi_{2}=0}=0, \\
& \left.\frac{\partial^{3} \mathrm{u}}{\partial \xi_{2}^{3}}\left(\xi_{2}, \mathrm{t}\right)\right|_{\xi_{2}=0}=\left.\frac{\mathrm{K}_{\mathrm{c}}}{\mathrm{EI}} \mathrm{u}\left(\xi_{2}, \mathrm{t}\right)\right|_{\xi_{2}=0},
\end{aligned}
$$

where $K_{c}$ is the equivalent stiffness, $E$ is Young's modulus, and $I$ is the moment of inertia.

The continuous conditions at the intermediate point C2 are

$$
\begin{aligned}
& \left.u\left(\xi_{1}, t\right)\right|_{\xi_{1}=\mu}=\left.u\left(\xi_{2}, t\right)\right|_{\xi_{2}=v}=0, \\
& \frac{d \varphi_{2 n}^{(1)}(\mu)}{d \xi_{1}}=-\frac{d \varphi_{2 n}^{(2)}(v)}{d \xi_{2}} \\
& \frac{d^{2} \varphi_{2 n}^{(1)}(\mu)}{d \xi_{1}}=\frac{d^{2} \varphi_{2 n}^{(2)}(v)}{d \xi_{2}} .
\end{aligned}
$$

The functions $\varphi_{2 \mathrm{n}}^{(1)}$ and $\varphi_{2 \mathrm{n}}^{(2)}$ are normal modes of Model 2

$$
\varphi_{2 \mathrm{n}}^{(1)}\left(\xi_{1}\right)=\sin \mathrm{k}_{\mathrm{n}_{2}} \xi_{1}-\frac{\sin \mathrm{k}_{\mathrm{n}_{2}} \mu}{\operatorname{sh} \mathrm{k}_{\mathrm{n}_{2}} \mu} \operatorname{sh} \mathrm{k}_{\mathrm{n}_{2}} \xi_{1}, \quad 0<\xi_{1}<\mu, \quad \mathrm{n}_{2}=1,2,3, \ldots,
$$

and

$$
\begin{aligned}
\varphi_{2 \mathrm{n}}^{(2)}\left(\xi_{2}\right)=\mathrm{D}_{1 \mathrm{n}} & {\left[\mathrm{D}_{2 \mathrm{n}}\left(\sin \mathrm{k}_{\mathrm{n}_{2}} \xi_{2}+\operatorname{sh} \mathrm{k}_{\mathrm{n}_{2}} \xi_{2}\right)+\mathrm{D}_{3 \mathrm{n}}\left(\cos _{\mathrm{n}_{2}} \xi_{2}+\operatorname{ch} \mathrm{k}_{\mathrm{n}_{2}} \xi_{2}\right)\right.} \\
& \left.+\mathrm{D}_{4 \mathrm{n}} \sin \mathrm{k}_{\mathrm{n}_{2}} \xi_{2}+\mathrm{D}_{5 \mathrm{n}} \operatorname{sh} \mathrm{k}_{\mathrm{n}_{2}} \xi_{2}\right], \quad 0<\xi_{2}<v, \quad \mathrm{n}_{2}=1,2,3, \ldots
\end{aligned}
$$

where 


$$
\begin{aligned}
& D_{1 n}=\frac{\operatorname{cosk}_{n_{2}} \mu-\sin k_{n_{2}} \mu \operatorname{cth} k_{n_{2}} \mu}{2\left(1+\cos k_{n_{2}} v \operatorname{ch} k_{n_{2}} v\right)+\frac{2 K_{c}}{E I} \frac{1}{k_{n_{2}}^{3}}\left(\cos k_{n_{2}} v \operatorname{sh} k_{n_{2}} v-\sin k_{n_{2}} v \operatorname{ch~} k_{n_{2}} v\right)} \\
& D_{2 n}=\cos k_{n_{2}} v+\operatorname{ch~} k_{n_{2}} v \\
& D_{3 n}=-\left(\sin k_{n_{2}} v+\operatorname{sh} k_{n_{2}} v\right) \\
& D_{4 n}=-\frac{2 K_{c}}{E I} \frac{1}{k_{n_{2}}^{3}} \operatorname{sh} k_{n_{2}} v \\
& D_{5 n}=\frac{2 K_{c}}{E I} \frac{1}{k_{n_{2}}^{3}} \sin k_{n_{2}} v \\
& n_{2}=1,2,3, \ldots
\end{aligned}
$$

where $k_{n_{2}}$ are the solutions of the characteristic equation.

$$
\frac{\sin k_{n_{2}} \mu}{\cos _{n_{2}} \mu-\sin k_{n_{2}} \mu \operatorname{cth} k_{n_{2}} \mu}-\frac{\sin k_{n_{2}} v}{\cos _{n_{2}} v-\sin k_{n_{2}} v \operatorname{cth} k_{n_{2}} v}=0 .
$$

Let

$$
\begin{aligned}
& \varphi_{2 \mathrm{n}}(\xi)= \begin{cases}\mathrm{C}_{2 \mathrm{n}} \varphi_{2 \mathrm{n}}^{(1)}(\xi) & 0<\xi<\mu \\
\mathrm{C}_{2 \mathrm{n}} \varphi_{2 \mathrm{n}}^{(2)}(1-\xi) & \mu<\xi<1,\end{cases} \\
& \mathrm{C}_{2 \mathrm{n}}=\frac{1}{\sqrt{\int_{0}^{\mu}\left[\varphi_{2 \mathrm{n}}^{(1)}\left(\xi_{1}\right)\right]^{2} \mathrm{~d} \xi_{1}+\int_{0}^{Y}\left[\varphi_{2 \mathrm{n}}^{(2)}\left(\xi_{2}\right)\right]^{2} \mathrm{~d} \xi_{2}}}
\end{aligned}
$$

The solutions of the tube vibration by the normal-mode method are 


\section{Distribution for ANL $91 / 30$}

\section{Internal}

Y. Cai (5)

S. S. Chen (5)

J. A. Jendrzejczyk

C. A. Malefyt (2)

T. M. Mulcahy

C. E. Till
R. A. Valentin

M. W. Wambsganss (3)

R. W. Weeks

ANL Patent Dept.

ANL Contract File

TIS Files (3)

\section{External}

DOE-OSTI for distribution per UC-406 (47)

ANL-TIS Libraries

Manager, Chicago Operations Office, DOE

Director, Technology Management Div., DOE-CH

D. L. Bray, DOE-CH

A. L. Taboas, DOE-CH

Materials and Components Technology Division Review Committee:

H. Berger, Industrial Quality, Inc., Gaithersburg, MD

M. S. Dresselhaus, Massachusetts Institute of Technology, Cambridge, MA

S. J. Green, Electric Power Research Institute, Palo Alto, CA

R. A. Greenkorn, Purdue University, West Lafayette, IN

C.-Y. Li, Cornell University, Ithaca, NY

P. G. Shewmon, Ohio State University, Columbus

R. E. Smith, Electric Power Research Institute, NDE Ctr., Charlotte, NC

O. P. Manley, DOE, Washington, DC

J. S. Coleman, DOE, Washington, DC

D. Frederick, DOE, Washington, DC

F. C. Moon, Cornell University, Ithaca, NY 

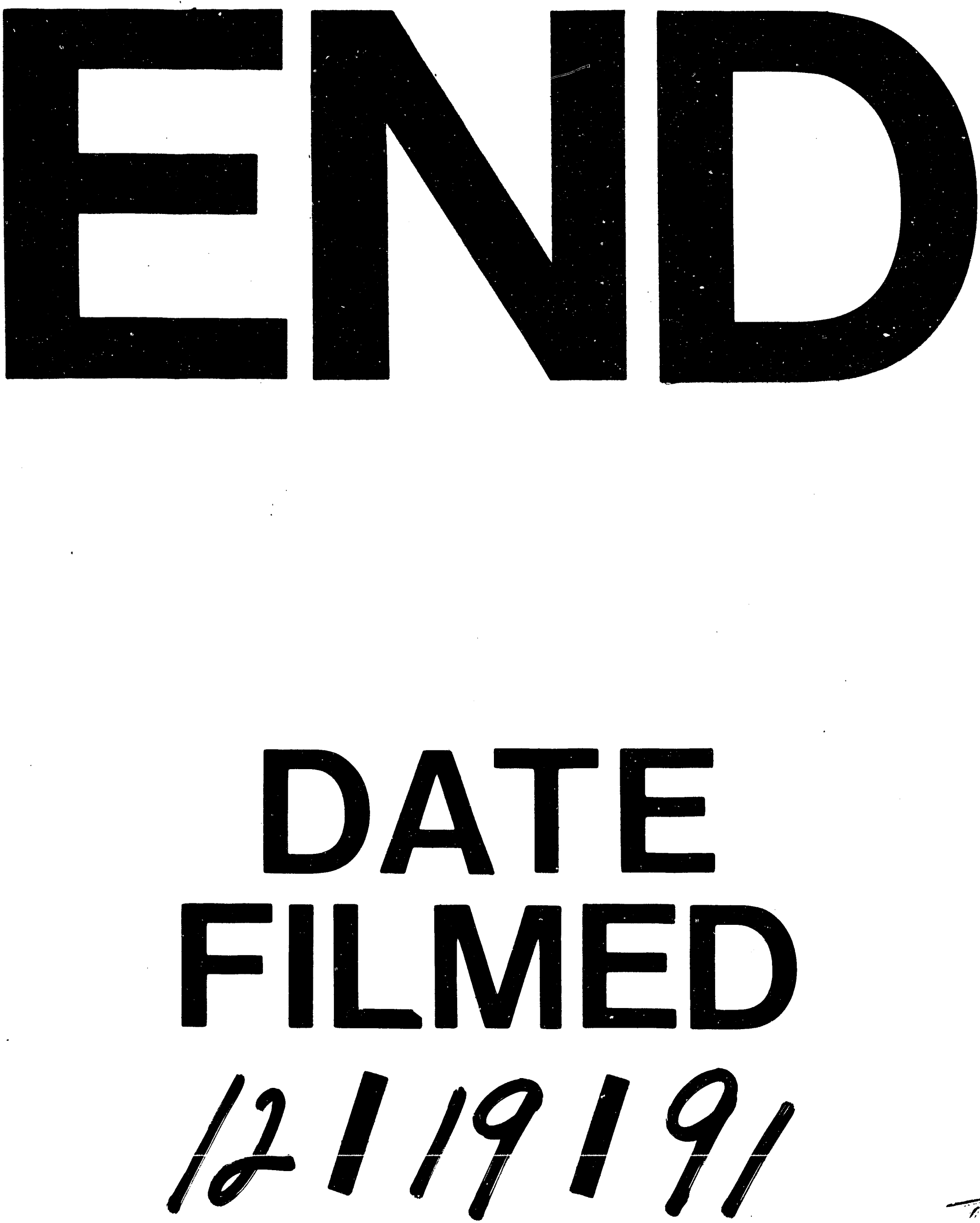
